\title{
Performance validation and manufacture feasibility for an advanced constructive system considering facilities integration
}

\author{
Carlos Rivera-Gomez ${ }^{a, *}$, Jose Perez-Fenoy ${ }^{b}$, Jose A. Entrenas-Angulo ${ }^{c}$, Martín Lopez-Aguilar ${ }^{c}$, \\ Carmen Galan-Marín ${ }^{\mathrm{a}}$

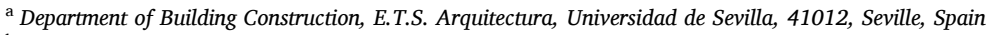 \\ ${ }^{\mathrm{b}}$ Andalusian Ceramic Technology Center, INNOVARCILLA Foundation, 23710, Bailen, Jaen, Spain \\ ${ }^{c}$ Department of Rural Engineering, Construction Engineering Area, University of Cordoba, 14004, Cordoba, Spain
}

\section{A R T I C L E I N F O}

\section{Keywords:}

Partition walls: facilities integration

Sustainable building: mechanical

characterization

Thermal and acoustic performance

Finite elements method

\begin{abstract}
A B S T R A C T
The growing demand to save material and energy resources, and increasing concern over environmental issues, are forcing solutions that entail a lower environmental impact of the materials and products used. This is particularly relevant for internal wall partitions which, due to their volume, greatly contribute to the environmental repercussion of buildings. A significant percentage of this impact is waste derived from the integration of plumbing and electricity installations. The present research deals with the development of a new ceramic system for partitions and internal facade sheets that enable the integration of facilities with minimum waste generation.

The proposed ceramic system ensures an appropriate thermal, acoustic and mechanical performance. In addition to the design description and manufacturing process, acoustic performance is measured by empirical validation, while thermal performance by numerical simulations via the finite element method (FEM). Mechanical performance is assessed by a set of experimental tests carried out on masonry walls subject to different load types, and by FEM simulation.

From the results obtained, it is possible to conclude that the innovative masonry unit fulfills all the thermal, acoustic and mechanical requirements prescribed for partition systems, even improving on the results for conventional solutions.
\end{abstract}

\section{Introduction}

In terms of climate breakdown, the current built environment is inadequately designed and managed in most cases, and resource waste throughout the life-cycle of buildings has a significant impact on the global environment. Additionally, due to increasing awareness of the effects of the contemporary development model on global heating, and the growing international movement towards high-performance/ sustainable buildings, the current eco-efficiency level paradigm of a building's products and systems is changing rapidly [1].

Masonry pieces and ceramic products are fundamental elements in today's construction systems, and must provide the necessary climate and comfort conditions for the optimal development of the daily activities of the building's users [2]. Non-load bearing walls (partitions and enclosures) prevail in the construction of residential buildings in Spain. In this context, the introduction of plumbing and electricity installations inside these walls is a later process that has disadvantages, as the increase in coating thickness and execution time, the reduction of physical properties by means of thermal and acoustic bridges like thermal and/or acoustic insulation, and the generation of a considerable amount of waste that is difficult to recycle, lead to a less sustainable building system by increasing energy costs [3].

A partition wall is a thin element built to divide the indoor space into rooms or other compartments. Generally, partition walls are non-load bearing. For a load-bearing wall, strength is an important design factor; a partition, on the other hand, needs only to be strong enough to support itself under normal service conditions. The main structural requirement of a partition wall is to have the necessary strength to support a surface suitable for decoration and the accidental impacts resulting from the occupation of the building. The solutions for partition wall units to meet such requirements include non-traditional brick masonry and other solutions, such as lightweight concrete blocks [4] or gypsum blocks [5] but, in Spain, they are still scarcely used relative to traditional brick masonry. However, the increasingly demanding

\footnotetext{
* Corresponding author.

E-mail address: crivera@us.es (C. Rivera-Gomez).
} 
regulatory requirements in terms of acoustic [6] and thermal [7] performance, and the need for compliance with optimal life-cycle and eco-efficiency targets [8-11] have driven a growing development in the design of products for these construction purposes. It should also be noted that, for new systems designs, the evaluation of mechanical behavior properties is a critical point to consider [12].

Traditional brick masonry systems are often manufactured without considering facilities integration, which requires a later operation consisting of wall grooves made by imprecise mechanical procedures. The use of these cutting machines necessarily leads to a loss of wall performance, especially with regard to acoustic and thermal insulation, and a weakening of the mechanical stability of the partition in some cases. The practice of breaking the wall surface involves the generation of nonreusable debris, as well as the need to subsequently add additional filling materials to close the open groove. This produces a considerable increase in the amount of waste generated during the construction process, not only in materials but also in the number of containers required to remove it. This increase in waste has an impact on a less sustainable construction model and, obviously, generates higher waste management costs.

As a result, one of the main advantages of the use of the most recent industrialized partition systems is to make the incorporation of installations easier, contrary to the use of the usual brick masonry walls that need grooves to fix electrical, communication and hydraulic installations. New partition systems also allow for considerable waste savings during the construction phase. This reduction in waste represents a significant advantage economically and environmentally as it eliminates or substantially reduces waste transportation costs and accounts for lower waste accumulation in sanitary landfills. In fact, the construction market is responsible for $50 \%$ of total waste accumulated in landfills, for the production of $30 \%$ of total $\mathrm{CO}_{2}$ emissions and for $40 \%$ of total energy consumption during the building's operation [13].

Partition walls have emerged as building sub-systems as a result of several factors, including the development of frame construction where internal walls are no longer required to have a load-bearing function. Due to emergent aspects like the speed of organizational and technological change, the increased number and complexity of services to be accommodated, quality and aesthetic issues and the need for acoustic separation of areas, the contemporary internal partition wall has had to adjust to these new requirements [14]. The most common interior partition system in Spain is a single wall made of hollow brick units (24

$11.5 \times 4-7 \mathrm{~cm}$ ), coated with $1.5 \mathrm{~cm}$-thick cement plaster on both sides, which results in a total wall thickness of 7-10 cm; ceramic hollow brick units have horizontal holes and present a regular geometry with four striated sides which allow good adhesion for any type of finish. As indicated above, the installations are placed after building the wall and before plastering, through the execution of grooves that accommodate the installations and which are later filled in with mortar (Fig. 1).

Virtually all traditional ceramic systems are made through masonry processes, so they rely heavily on the execution method. The cost increases involved in this phase, as well as the popularization of lightweight framework systems, have forced the ceramic sector to propose alternative solutions. As a result, nowadays large-format pieces and masonry panels provide additional optimization than traditional bricks. Nevertheless, these systems continue to be underused, mainly in the case of panels. Furthermore, despite the fact that a larger format reduces execution time, the integration of facilities is only partially solved, with the inevitable assumption of constructive element section reduction giving rise to thermal and acoustic bridges, as well as mechanical weakening that seriously undermines the executed solution. From the construction process sustainability point of view, practically all systems require destruction-reconstruction techniques that involve high waste production. These operations are required for both the dimensional adjustment of the panels and for the introduction of facilities (not integration).

The work presented here deals with the development of a ceramic solution for partition and internal facade sheet masonry walls that allow for the integration of facilities with a minimum generation of waste, as well as complying with the necessary mechanical and comfort requirements. This research validated the partition wall solution in terms of mechanical, thermal and acoustic performance, and the experimental results are discussed in terms of empirical and simulation procedures. Details of the design process of the ceramic masonry system are also provided. The major novelty of the present study is not only the proposal of an advanced ceramic system that considers facilities integration but the design of a block mechanization method at the factory that enables open longitudinal punctures perpendicular to the extrusion line to be made.

\section{Experimental program}

\subsection{Description of the system components and specifications}

\subsubsection{Shape and geometry}

The proposed system is a solution for the construction of selfsupporting internal facade sheet masonry walls and building partitions, composed by the bonding of large-format hollow ceramic blocks with horizontal punctures, joined by a plaster-based assembly paste PUMA GROUP brand (MORCEM $®$ ) [15] and finished with different types of coating. The partition wall is assembled by placing the ceramic blocks in consecutive rows. Horizontal joints are a tongue-and-groove scheme, while vertical joints are formed by stacking blocks. In both cases, the joints are filled with the plaster-based assembly paste, consisting of a mixture of water and a gypsum or plaster base adhesive, which joins the gaps between pieces penetrating the horizontal perforations, forming average-thickness horizontal linkages. The blocks' format is modulated for a height of $3 \mathrm{~m}$ between floor and ceiling so that the partition is executed with five courses, plus a special-height piece, or by adding one more course and cutting it to the necessary size.

The main system novelty lies in making two perforations by block

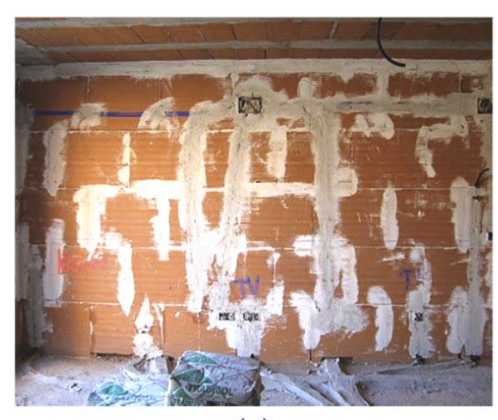

(a)

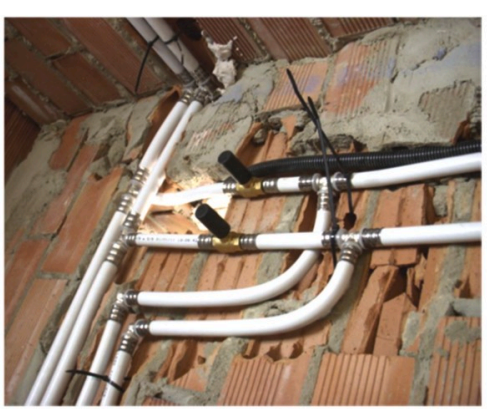

(b)

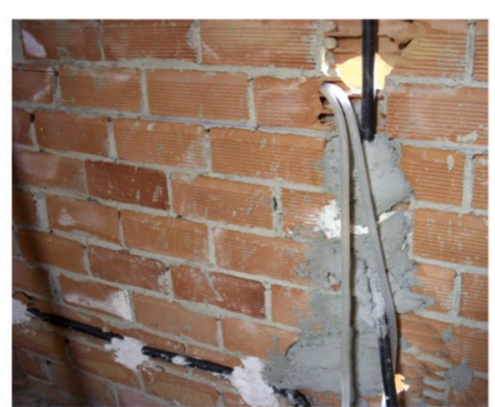

(c)

Fig. 1. (a), (b) and (c): Different views of the effect of the process of placing installations inside a traditional masonry wall. 
perpendicular to the extrusion direction of the piece in such a way that once finished, not only horizontal but also vertical internal channels to locate installations would be available. In the case of flexible installations, this would eliminate the on-site cuts, and in the case of rigid installations, greatly reduce the waste generated and the execution time of this phase. The size of the perforations is calculated to allow the passage of installations of different thickness (See Fig. 2).

The system consists of two basic blocks: The first is designed for the execution of single or double interior partitions. This piece has dimensions of $62 \quad 53.3 \quad 7 \mathrm{~cm}$ (width $\mathrm{x}$ height $\mathrm{x}$ thickness). The second piece is specifically conceived to execute the internal facade sheet. The

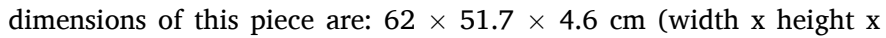
thickness) (See Fig. 3). The partitions and facade walls have surfaces that allow coating with tiling or with a plaster trim of little thickness (10 $\mathrm{mm}$ ) or with laminated plasterboard adhered on the partition. When there is a fire-resistance requirement, the plaster trim must be $15 \mathrm{~mm}$ in order to improve partition performance.

\subsubsection{Production technology}

The design of the proposed systems involved some modifications in the modelling phase of the pieces prior to cooking. Such modifications included the manipulation of the geometry of the blocks once their general volume was formed in the extrusion phase. These operations were carried out by reengineering the manufacturing process, introducing an intermediate phase in which two lateral punctures perpendicular to the extrusion direction were made to each piece (Fig. 4).

The manufacturing disadvantages derived from the design of innovative pieces such as the adjustment of the manufacturing times, geometric calibration and final control of the blocks once cooked involved several industrial tests until a suitable and reproducible process was achieved. This process finally guaranteed blocks in series that were uniform and without deformations or retraction that could enable the facilities to be integrated with minimum on-site handling (Fig. 5).

\subsection{Validation of the masonry's mechanical behaviour}

\subsubsection{Safety in use tests}

Even though the proposed system is to be used in non-load bearing walls, it is important to ensure its structural stability in terms of the key loading conditions, in line with the European Technical Assessment issued in accordance with EU regulations applicable to these systems [16]. To assign a certain use, it is essential to identify to what extent the partition wall is able to bear impact and eccentric compression loads, thus determining the appropriate behavior of the partition under this type of mechanical stress. These tests involve the combined evaluation of the blocks' mechanical behavior and the plaster-based assembly paste connecting the blocks. Additionally, impact tests and eccentric compressive loading tests were carried out on a prototype wall built in a test cell. This prototype wall was also used to assess the acoustic performance of this new partition wall technology (Fig. 6). The prototype wall was built in a steel frame that belongs to a test cell with the following characteristics: $4.60 \mathrm{~m}$ in length and $3.20 \mathrm{~m}$ in height, with a free end without bracing. It also had a door of $0.90 \mathrm{~m}$ width located at $0.70 \mathrm{~m}$ from the braced end. The connections to the steel frame were made using the same assembly paste used for the connection between blocks. The prototype wall tested was a single-leaf ceramic wall executed with the system's large-format pieces ( $62 \quad 53.3 \quad 7 \mathrm{~cm}$ ). The masonry wall was covered with a $15 \mathrm{~mm}$ layer of plaster on both sides, and electrical and plumbing installations were placed inside. The prototype wall started on a $10 \mathrm{~mm}$-thick EEPS band fixed to the base of the support by means of a plaster-based adhesive. In the connection of the wall to the door frame in the upper part, the same band was available. For the correct procedure of the test, a minimum of 15 days was allowed for the assembly paste and plaster curing process.

2.2.1.1. Assessment of behavior in eccentric compressive tests. The EU regulation for these partition systems [16] defines two states in relation to which the resistance to impact and eccentric compression load should

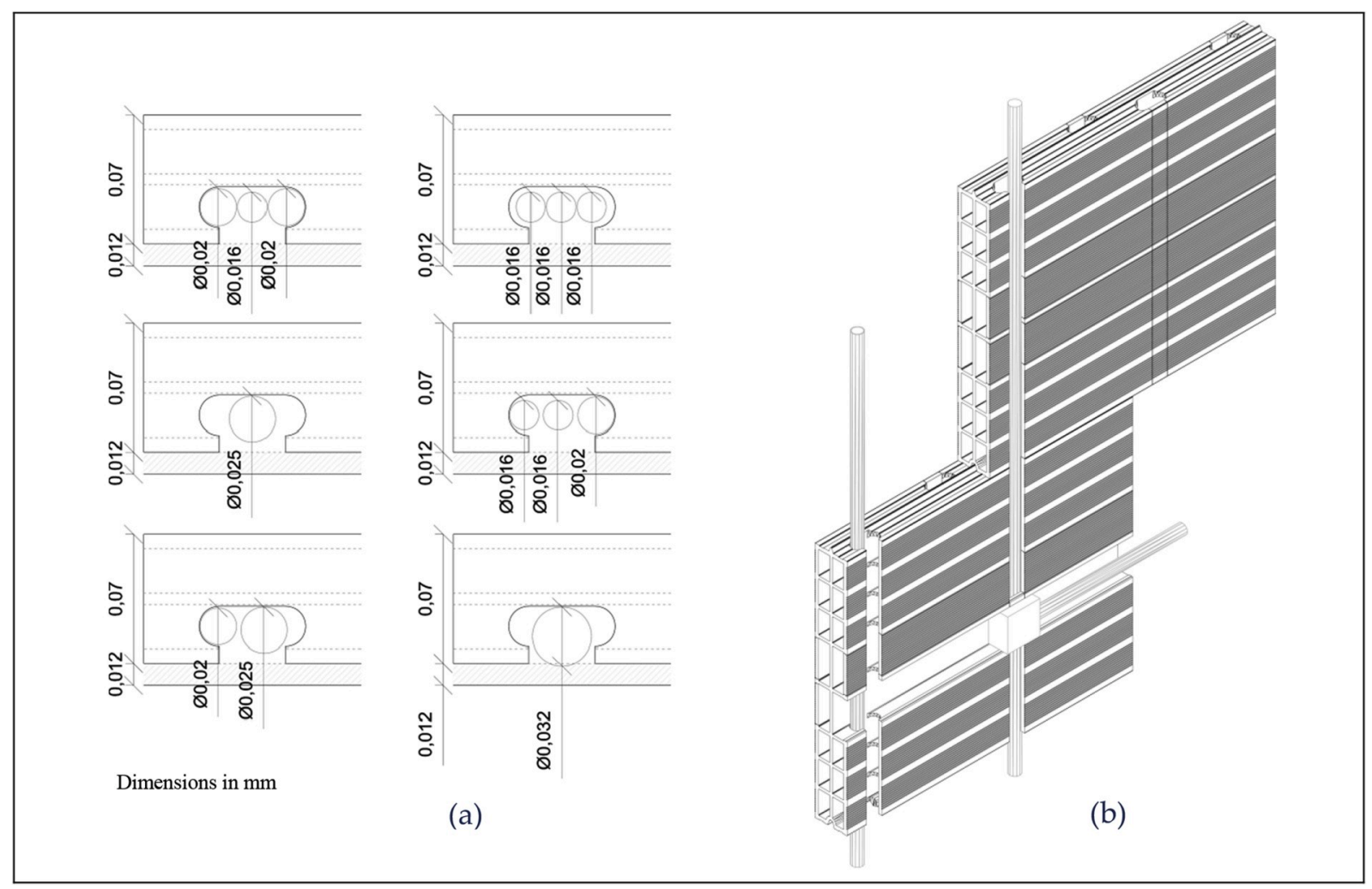

Fig. 2. Ducts views: (a) different installations tubes, from 12 to $32 \mathrm{~mm}$. And (b) facilities within the system scheme perspective. 


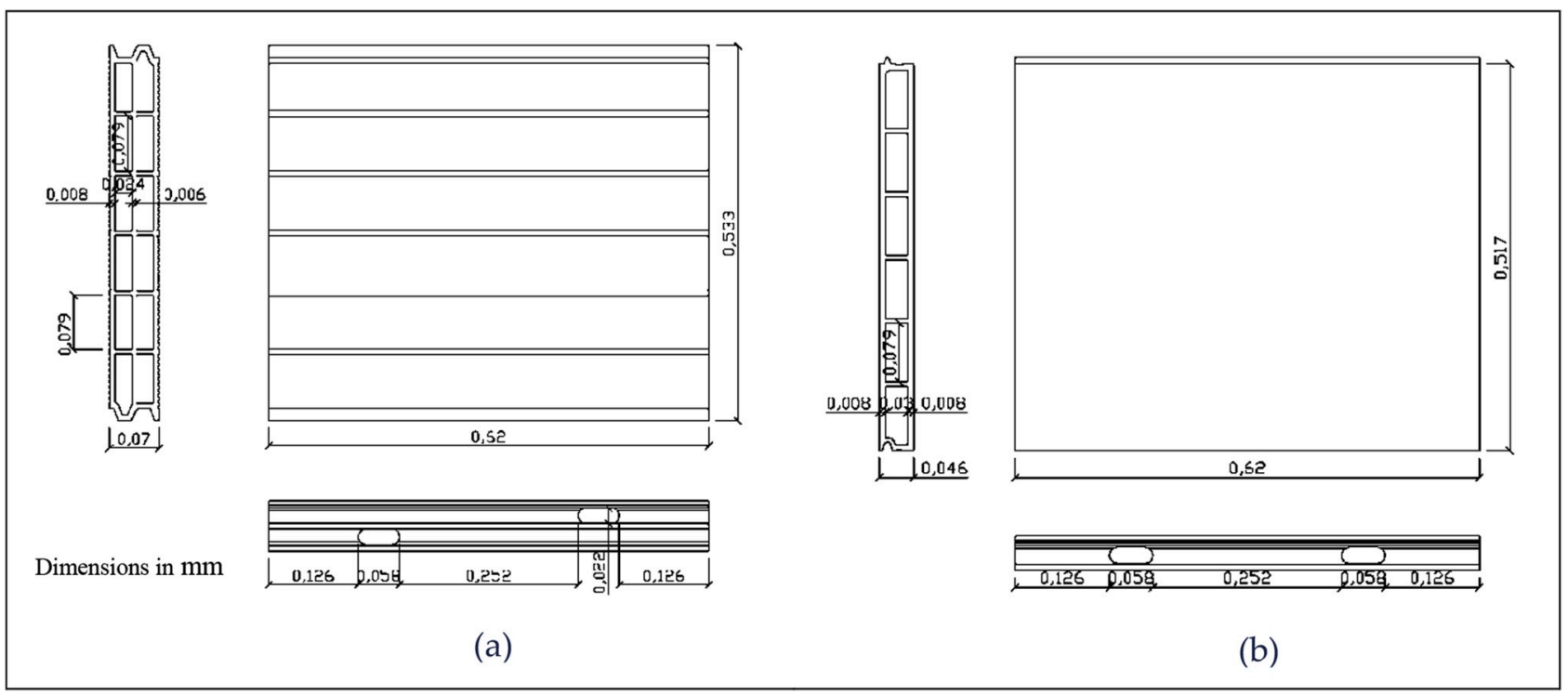

Fig. 3. Basic blocks of the proposed system views and dimensions: (a) block piece for partitions. And (b) block piece for the solution of façades internal sheet.

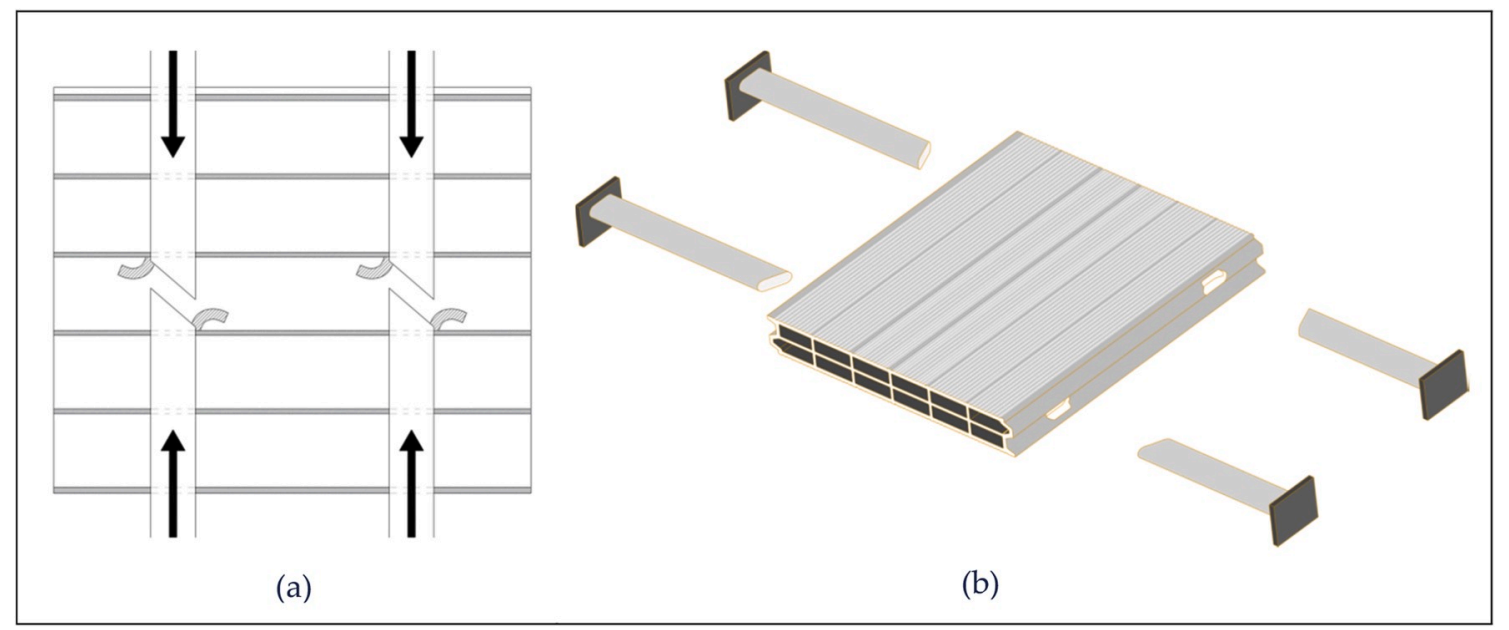

Fig. 4. (a) Scheme of the simultaneous puncture directions in opposite block sides. And (b) Image of the four punches that perforate the piece after the extrusion phase.

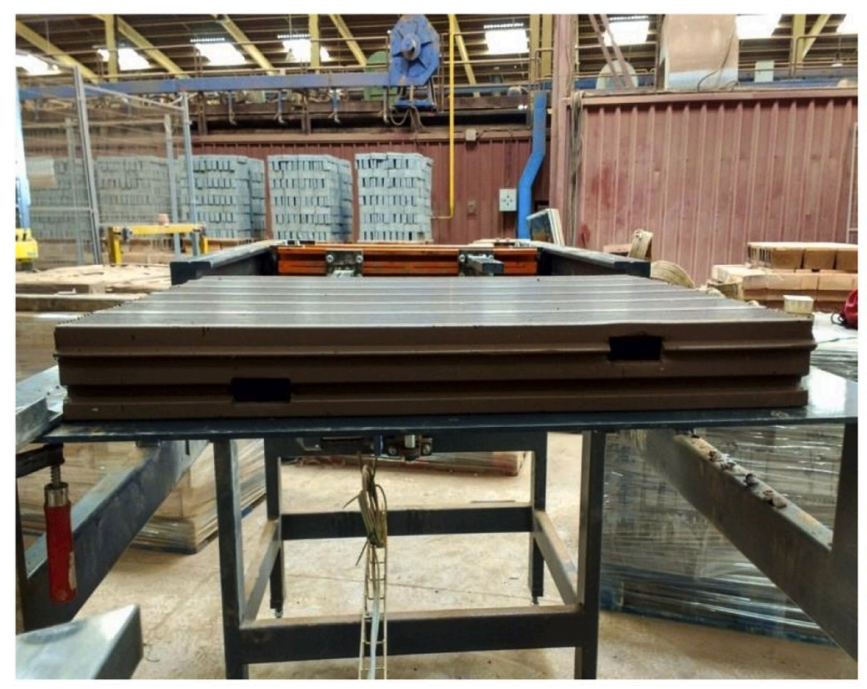

(a)

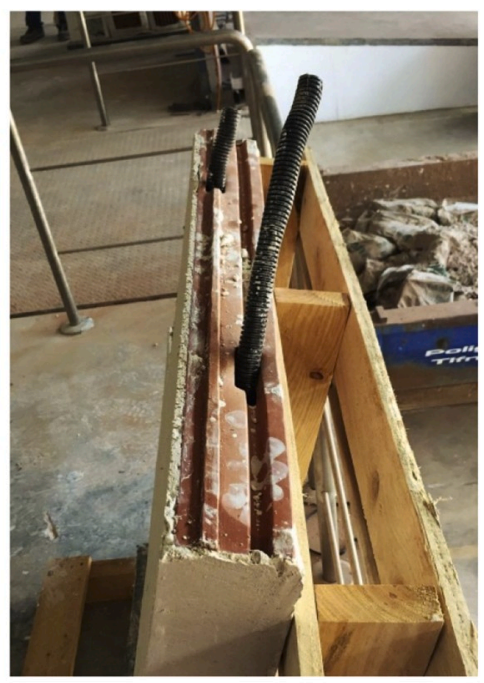

(b)

Fig. 5. (a) Image of the piece once molded and cooked. And (b) Facilities integrated inside a block. 


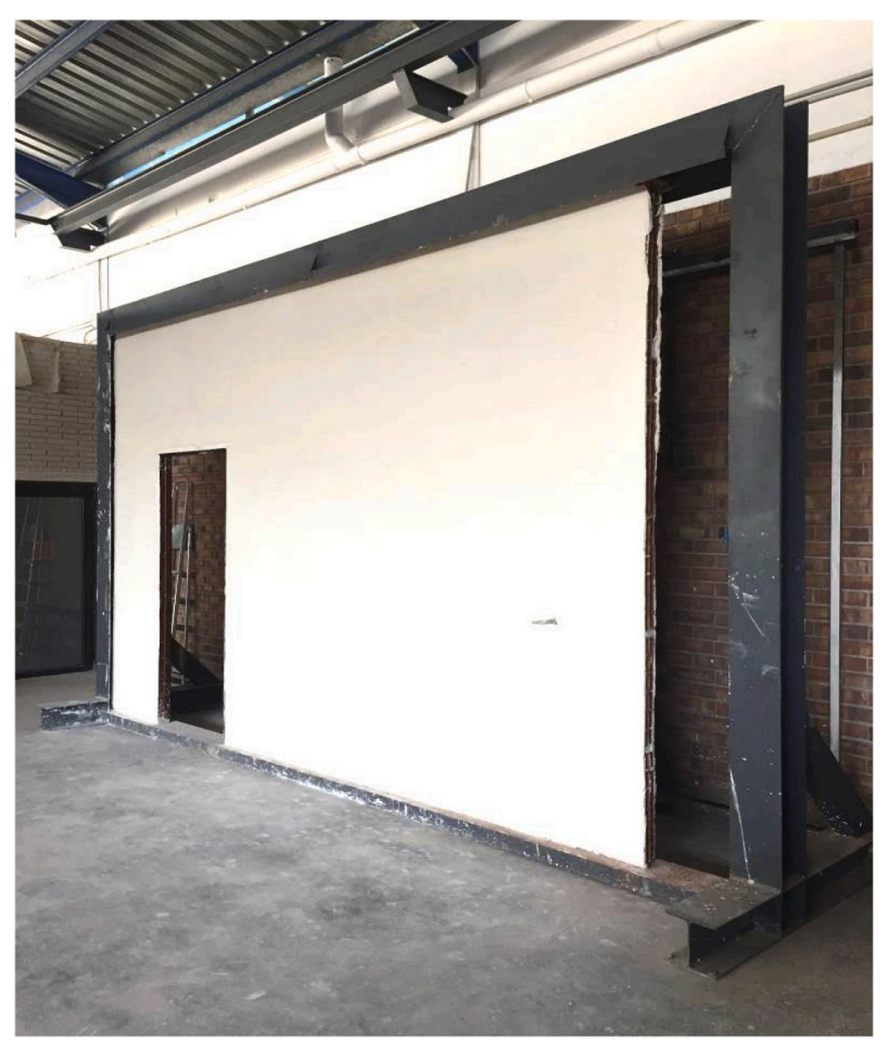

Fig. 6. Image showing the appearance of the prototype wall once finished in the test cell.

be verified, namely the state that foresees the structural damage and the state that ensures adequate behavior under service loads. For each state, different levels of loading associated to different categories of use are defined from the loading area categories stated in EC1 [17]. The essential requirement considering safety in use laid down in Council Directive 89/106/EEC [18] is as follows:

The construction works must be designed and built in such a way that it does not present unacceptable risks of accidents in service or in operation such as slipping, falling, collision, burns, electrocution, and injury from an explosion.

Regarding resistance to horizontal and eccentric loads, the partition should have sufficient mechanical resistance and stability to ensure that the safety of the occupants is not endangered. The aspects of performance in this section relate to the structural integrity of the partition kit by means of indicating use categories relating to EN 1991-1-1 [17].

According to the European guidelines for technical approval of partition walls [16] there are two loading categories: A and B. For anchoring the supports to carry out the tests corresponding to each load category, the following systems were used: For category A (mechanical anchoring), $\varnothing 8 \times 60 \mathrm{~mm}$ lag screw and universal plastic plug Ø10 50 $\mathrm{mm}$. For category B (chemical anchoring), chemical plug FIS P $300 \mathrm{~T}$, FIS cannula H $16 \quad 85 \mathrm{~mm}$ and zinc-plated M 8 threaded rod (see Fig. A1 in the Appendix).

For the test procedure, two supports (metal brackets) were used to simulate the behavior of a rack in a centered position on the prototype wall at a height of $1.60 \mathrm{~m}$ above its base (Fig. 7). The supports were separated from each other by a distance of $0.50 \mathrm{~m}$. Each support was mechanically anchored by two $\varnothing 8 \times 60 \mathrm{~mm}$ lag screws and a $\emptyset 10 \quad 50$ $\mathrm{mm}$ universal plastic dowel separated by $0.15 \mathrm{~m}$ in the vertical direction. A $500 \mathrm{~N}$ load was applied to the supports, separated at $0.30 \mathrm{~m}$ from the plane of the wall, performing 30 cycles of loading and unloading at a speed of approximately $2000 \mathrm{~N} / \mathrm{min}$. The linear transducer for the data collection was fixed to the back of the test sample, taking the measurements in the central point and equidistant to each of the shelving squares. This means that it should have sufficient mechanical resistance and stability to withstand accidently large static or dynamic loads and the action of persons or objects, and should not fully or partially collapse releasing dangerous (sharp or cutting) fragments, or put persons at risk of falling through, particularly at a change of level, or endanger their safety.

Regarding the results of the functional damage, there was no residual deformation of the partition measured at the same point at $5 \mathrm{~min}$ after the end of the 30 cycles. No damage to the sample or anchoring elements was observed. The maximum deviation was lower than that permitted: $1 / 500$ of the height of $5 \mathrm{~mm}$. The transverse deformation results are equal to 0.05 for all cycles from 1 to 30 . Considering the structural damage, there was no residual deformation of the partition measured at the same point at $5 \mathrm{~min}$ after the end of the 30 cycles. No damage to the sample or anchoring elements was observed. The maximum deviation was lower than that permitted: $1 / 500$ of the height of $5 \mathrm{~mm}$. Tests were carried out on the same supports used for the execution of Category A functional damage. A $1000 \mathrm{~N}$ load was applied to the supports, separated at $0.30 \mathrm{~m}$ from the surface of the sample. This load contined to be applied for $24 \mathrm{~h}$. The linear transducer for the data collection was fixed to the back of the test sample, taking the measurements in the central point and equidistant to each of the shelving squares. The structural damages results are shown in Table A1 in the Appendix.

After the test, the following structural results were observed: The residual deformation of the partition measured at the same point at 5 min after removing the load was $0.10 \mathrm{~mm}$. The increase in deflection during the test stabilized at $0.25 \mathrm{~mm}$. There was no collapse or other failures to compromise safety.

To verify possible functional damage in the eccentric vertical load test (Category B), two supports (metal brackets) were placed as a shelf in a position centered on the sample at a height of $1.60 \mathrm{~m}$. The supports were separated from each other by a distance of $1.00 \mathrm{~m}$. Each support was fixed by chemical anchors separated at $0.60 \mathrm{~m}$ in the vertical. Then, a load was applied, separated at $0.30 \mathrm{~m}$ from the surface of the sample, of $2000 \mathrm{~N}$ to the supports, performing 30 cycles of loading and
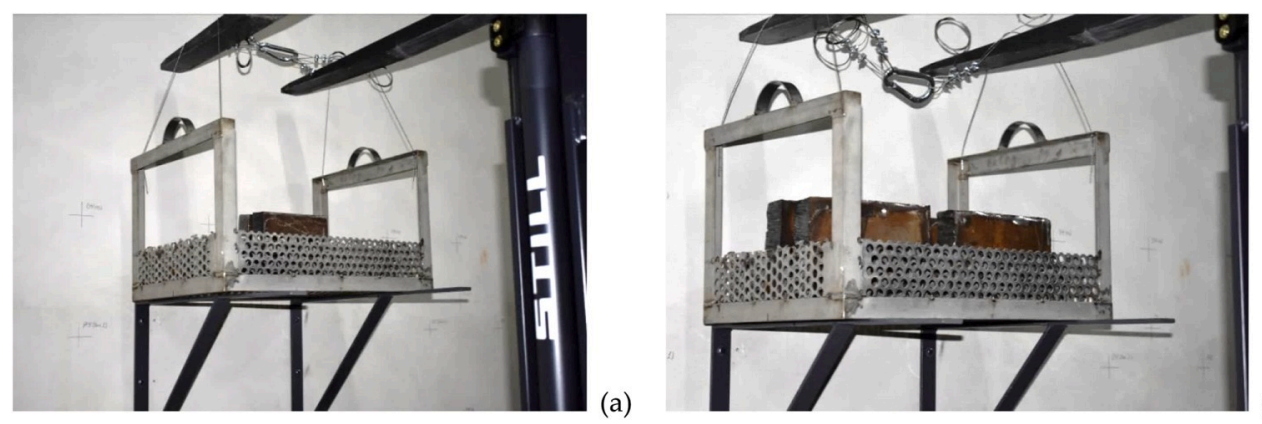

(b)

Fig. 7. Vertical eccentric load tests devices, (Category A); (a), Functional damages and (b), Structural damages. 
Table 1

Classification of the tested partition.

\begin{tabular}{|c|c|c|}
\hline Sample & Category & Result \\
\hline $\begin{array}{l}\text { Single-leaf ceramic wall executed with large- } \\
\text { format pieces ( } 62 \quad 51.7 \quad 4.6 \mathrm{~cm} \text { ). The } \\
\text { masonry wall is equipped with a layer of } 15 \mathrm{~mm} \\
\text { of plaster on both sides and houses electrical and } \\
\text { plumbing installations inside. }\end{array}$ & $\begin{array}{l}\text { - Load } \\
\text { Category: A * }\end{array}$ & SUITABLE \\
\hline $\begin{array}{l}\text { The partition starts on a } 10 \mathrm{~mm} \text { thick EPS strip and } \\
\text { has a } 15 \mathrm{~mm} \text { thick plaster coating on both sides. }\end{array}$ & $\begin{array}{l}\text { - Use Category: } \\
\text { III ** }\end{array}$ & \\
\hline
\end{tabular}

unloading at a speed of approximately $2000 \mathrm{~N} / \mathrm{min}$. In this test, the linear transducer for the data collection was fixed to the back of the test sample, taking the measurements in the central point and equidistant to each of the shelf supports (see Table. A2 in the Appendix).

The summary of functional damage results is specified below: The residual partition damage measured at the same point at 5 min after the end of the 30 cycles was $0.80 \mathrm{~mm}$. An increase in the opening of the horizontal fissure caused by the impact of soft body B5 was observed. Deterioration was observed next to the upper anchor of the right bracket (Fig. 8 a). The maximum deviation was less than that permitted: 1/500 of the height of $5 \mathrm{~mm}$.

To verify possible structural damage in the eccentric vertical load test (Category B), two supports (metal squares) similar to the previous ones were placed as a shelf in a position centered on the sample at a height of $1.60 \mathrm{~m}$, on the basis of the sample. The supports are separated from each other by a distance of $1.00 \mathrm{~m}$. Each support was fixed through chemical-type anchors separated at $0.60 \mathrm{~m}$ in the vertical. Then a load was applied, separated at $0.30 \mathrm{~m}$ from the surface of the sample, of 4000 $\mathrm{N}$ to the supports. This load was applied for $24 \mathrm{~h}$. The linear transducer for the data collection was fixed to the back of the test sample, taking the measurements in the central point and equidistant to each of the shelving squares. At the beginning of the test, one of the anchors of the supports collapsed, and the test was halted (Fig. 8 b).

2.2.1.2. Impact tests. According to EOTA guidelines [19], two distinct types of impact resistance should be considered, namely rigid- and soft-body impact resistance, to stimulate resistance of the wall to the projection of objects or to collision by building occupants. Rigid impact is produced with a steel sphere, while soft impact is made by the collision of a bag of specified geometry and mass. The steel sphere should have a diameter of $50 \mathrm{~mm}$ or $63.5 \mathrm{~mm}$ and a weight of $0.5 \mathrm{~kg}$ or $1.0 \mathrm{~kg}$ when verifying safety-in-use impact and serviceability impact resistances, respectively. The Rigid body impact results (Category III) are shown in Table A3 in the Appendix and Fig. 9.

Regarding the results of functional damage in the rigid-body impact test (Category III), the regulations state that marks caused by the impacts are permitted (Fig. 9). No other damage to the sample was observed. The behavior of the wall relative to soft-body impact was obtained by using a soft body consisting of a bag whose geometry is specified in EOTA [19], filled with glass spheres of $3 \mathrm{~mm}$ diameter and total mass of $50 \mathrm{~kg}$ (Fig. 10).

To measure functional damage in the soft-body impact test (Category III), two sets of three impacts were made at the same sample point, plus an additional series at $0.15 \mathrm{~m}$ from the door. Series 2: position near the free end $(70 \mathrm{~cm}$ from the free end). Series 1: position centered on the blind part of the sample, and Series 3: position $15 \mathrm{~cm}$ from the door. The

Table 2

Actions classification on partition elements.

\begin{tabular}{ll}
\hline Category of use $^{\text {a }}$ & Horizontal resistance $(\mathrm{kN} / \mathrm{m})$ \\
\hline C5 & 1,5 \\
C3, C4, E, F & 0,8 \\
Other cases & 0,4 \\
\hline
\end{tabular}

a See Table 3.1 CTE DB-SE-AE [20].
$50 \mathrm{~kg}$ spherical bag was placed at a height of $1.50 \mathrm{~m}$ measured on the basis of the sample, with $120 \mathrm{Nm}$ power equivalent to a height of fall of $0.24 \mathrm{~m}$. The door remained closed during the test, its correct operation checked after each impact. The maximum deflection of the partition in each impact was recorded, as well as its residual deformation $5 \mathrm{~min}$ after. The transmitter for data collection was fixed to the back of the test sample coinciding with the point of impact. The functional and structural damage results and the structural damage results (series 5) corresponding to Category III are shown in Tables A4 and A5 respectively in the Appendix and exposed in Fig. 11.

In order to verify structural damage in the soft-body impact test (Category III), an impact at the most unfavorable point of the sample ( $35 \mathrm{~cm}$ from the free end) was made. For this, a $50 \mathrm{~kg}$ spherical bag was used at a height of $1.50 \mathrm{~m}$ measured on the basis of the sample, with an energy of $300 \mathrm{Nm}$ equivalent to a drop height of $0.61 \mathrm{~m}$. The maximum deflection of the partition in the impact was recorded, as well as its residual deformation $5 \mathrm{~min}$ after. The transmitter for data collection was fixed to the back of the test sample coinciding with the point of impact.

After the test, the following functional damage was observed: Impact 2 (series 2), a horizontal crack appeared on the back of the sample that ran from the free side to the door. The fissure appeared at a height of 1.5 $\mathrm{m}$ coinciding with the joint between the pieces of the third and fourth courses. The development of the fissure was horizontal. After impact 3 (series 2), the crack became visible on the front of the sample. There was also a gypsum plaster surface detachment on the back of the sample at the junction with the door trim. As a result of Impact 1 (series 1), there was a new gypsum plaster surface detachment on the back of the sample at the junction with the door frame. In the rest of the impacts corresponding to series 1 and 3, no new fissures, flaws or increase in the fissure appeared in series 2 . The functional damage results can be summarized thus: Functional failure in the sample did not occur. Maximum residual deformation after the three impacts of each series was greater than $5 \mathrm{~mm}$ in all cases. The deflection increments during the test were stable. After all impacts, the door performance was correct.

After the test, the following structural damage was observed: After the impact, the horizontal fissure that appeared in B4 (Series 2) was accentuated both on the front and rear part, being clearly visible. A new fissure with deformation on the front of the sample appeared. This fissure was located at the junction of one of the sides of the pre-frame at the height of $1.45 \mathrm{~m}$. There was no detachment of material. The structural damage results can be summarized thus: No penetration occurred. There was no collapse or other failures that compromised safety. The operation of the door was correct. The diagram of impacts and damage on both sides of the partition are shown in Figures A2, A3 and A.4 in the Appendix.

2.2.1.3. Results analysis. The analysis and conclusions of the safety-inuse and stability test results show that the partition, according to the description made, is suitable for Category III use and Category A load. The test outline according to the standards' classification is shown below (Table 1).

\subsubsection{Mechanical behavior simulation}

The use of the finite element method (FEM) simulation is clearly an advantage since the cost of mechanical performance tests is high, due to the number of specimens needed, to the cost of manufacturing and that of the laboratory testing equipment to be used. The simulation allows an approximation to the real behavior of the element to be used in all situations of use, combining all the physical variables of the materials used and the geometrical characteristics of the element. The results analysis makes it possible to determine the initially suitable physical-geometrical values to be contrasted by testing the real model in the laboratory.

2.2.2.1. Calculation basis. Spanish regulation CTE DB-SE-AE (Codigo Tecnico de la Edificacion, Documento Basico: Seguridad Estructural, 


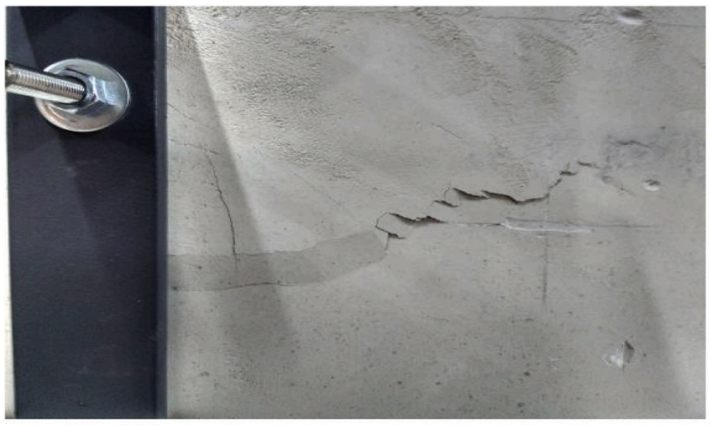

(a)

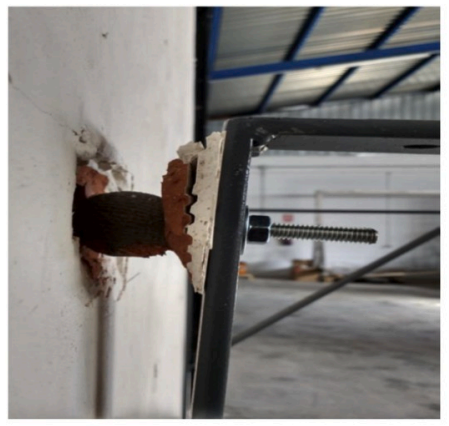

(b)

Fig. 8. Vertical eccentric load tests (Category B); (a) Deterioration next to the upper anchor of the right bracket and (b) Chemical anchoring Collapse at the beginning of the test.

Table 3

Partial safety factors for the actions.

\begin{tabular}{lll}
\hline Type of action & Unfavorable & Favorable \\
\hline Permanent & 1,35 & 0,80 \\
Variable & 1,50 & 0,00 \\
\hline
\end{tabular}

Therefore, the following combinations should be analyzed.

Acciones en la Edificacion, - Building Technical Code, Basic Document: Structural Safety, Actions in Buildings) [20], establishes in article 3.2, paragraph 3 that the dividing elements must support the load indicated in Table 2.

The load was applied at $1.2 \mathrm{~m}$ height. The partitions performance analysis with respect to the horizontal action was conducted in accordance with the verification procedure of the ultimate breaking state, according to which the partition is considered to have sufficient strength if the following condition is achieved:

Ed Rd

Where:

Ed: Effect of the actions' calculated value.

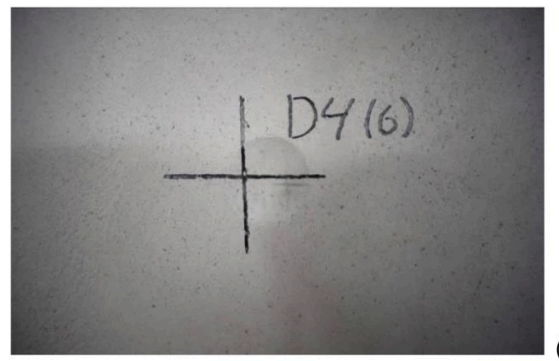

(a)
Rd: Corresponding resistance calculated value.

The effect of the actions' calculated value was determined through combinations of actions in the form:

$\begin{array}{llll}\gamma_{\mathrm{G}} & \mathrm{G} & \gamma_{\mathrm{Q}} & \mathrm{Q}\end{array}$

Where:

$\gamma_{\mathrm{G}}$ : Partial safety coefficient of the permanent actions for the verification of the ultimate breaking state in a persistent situation.

G: Characteristic value of the partition's own weight.

$\gamma_{\mathrm{G}}$ : Partial safety coefficient of the variables for checking the ultimate breaking state in a persistent situation.

Q: Characteristic value of the horizontal action, described above.

The following table was taken into account in the results interpretation (Table 3).

\section{$\begin{array}{llll}1.35 & \mathrm{G} & 1.50 \quad \mathrm{Q}\end{array}$ \\ $\begin{array}{llll}0.80 & \mathrm{G} & 1.50 \quad \mathrm{Q}\end{array}$}

Experience shows that the rupture of the partition is generally preceded by a massive development of cracking by traction in the joints,

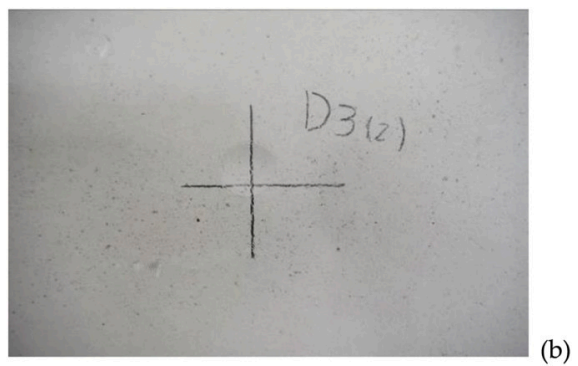

Fig. 9. Rigid body impact results: (a), $6 \mathrm{Nm}$ power and (b), $10 \mathrm{Nm}$ power.

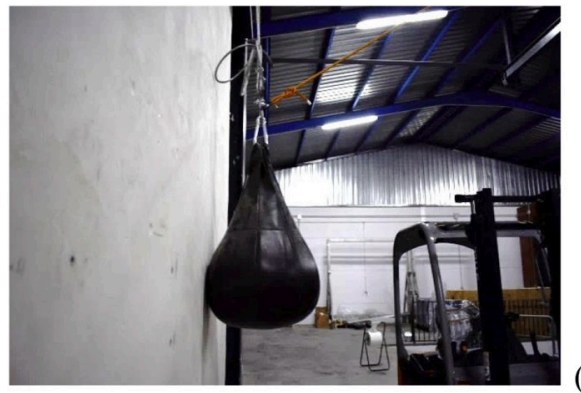

(a)

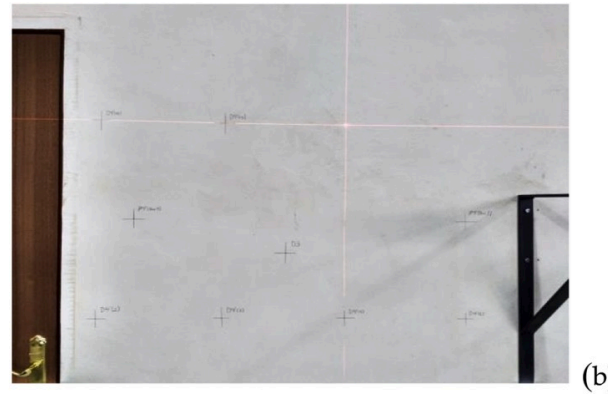

Fig. 10. Soft body impact test: (a) bag with small glass spheres and (b) impact points marking. 
Table 4

Mechanical properties of the materials used.

\begin{tabular}{|c|c|c|c|}
\hline Mechanical property & $\begin{array}{l}\text { Fired } \\
\text { clay }\end{array}$ & $\begin{array}{l}\text { Plaster-based } \\
\text { assembly paste }\end{array}$ & Standard/test \\
\hline $\begin{array}{l}\text { Elasticity module, E (N/ } \\
\mathrm{mm}^{2} \text { ) }\end{array}$ & 19200 & 1430 & $\begin{array}{l}\text { UNE-EN } 14146 \\
{[22]}\end{array}$ \\
\hline Poisson's coefficient, $\mu$ & 0,171 & 0,192 & $\begin{array}{l}\text { ASTM C-885-87 } \\
{[23]}\end{array}$ \\
\hline $\begin{array}{l}\text { Shear module, G (N/ } \\
\mathrm{mm}^{2} \text { ) }\end{array}$ & 8200 & 600 & $\begin{array}{l}\text { UNE-EN 843-2 } \\
{[21]}\end{array}$ \\
\hline $\begin{array}{l}\text { Compression strength } \\
\left(\mathrm{N} / \mathrm{mm}^{2}\right)\end{array}$ & 12,4 & 3.0 & ASTM C597 [24] \\
\hline $\begin{array}{l}\text { Tensile strength (N/ } \\
\mathrm{mm}^{2} \text { ) }\end{array}$ & 4,1 & 1,0 & $\begin{array}{l}\text { Ricardo et Al. } \\
\text { (2001) [25] }\end{array}$ \\
\hline $\begin{array}{l}\text { Specific weight }(\mathrm{kN} / \\
\left.\mathrm{m}^{3}\right)\end{array}$ & 17,66 & 9,90 & $\begin{array}{l}\text { Rosell et Al. (2011) } \\
\text { [26] }\end{array}$ \\
\hline
\end{tabular}

which constitute weakness planes. Therefore, the only combination

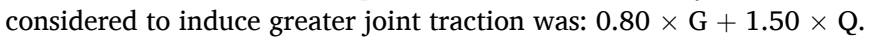

2.2.2.2. Tests performed. The partition component materials present the following mechanical properties. The results of both the cooked clay material and the gypsum assembly paste were calculated by laboratory tests. The table below shows the standard used in each case. Regarding gypsum assembly paste, the determination of the dynamic elasticity module was carried out from the fundamental frequency of vibration of bending specimens ( $100 \mathrm{~mm}$ distance between supports) subjected to impact with an instrumented hammer. The signal was captured by an accelerometer (Brüel \& KJaer, DeltaTron 4507-B, Denmark) according to UNE-EN 843-2 [21] and processed by a Pulse LAN-XI frequency analyzer (Brüel \& KJaer, Denmark). The elasticity module was calculated according to ASTM C 1259-01, assuming a Poisson coefficient value of 0.17 , which is considered a common value in other porous ceramic materials with a coarse microstructure, such as refractory materials (Table 4).

The partition strength calculation value depends on the strength calculation of the materials involved, $\mathrm{f}_{\mathrm{d}}$, which, in general, can be expressed as a quotient between the characteristic strength, $\mathrm{f}_{\mathrm{k}}$, and the material safety coefficient, $\gamma$ (Table 5).

$f_{d} \frac{f_{k}}{\gamma}$

To carry out the simulations, the following parameters were considered: Category of execution B and control of manufacturing I, consequently, $\gamma \quad 2.2$, resulting in the strength calculation of some materials (Table 6):

2.2.2.3. Simulation by FEM. A series of simulated tests were carried out using the RFEM, version 5.15, of Dlubal Software GmbH, calculation program by finite element method (FEM) [27]. The analysis was made on a model corresponding to a $1 \mathrm{~m}$-wide partition portion. This portion was $3 \mathrm{~m}$ in height and $7 \mathrm{~cm}$ in thickness, influenced by the horizontal load described above, and was modeled by means of flat plate-like elements of $1 \mathrm{~m}$ thickness.

The following calculation options were considered:

The cross-section was discretized by a flat finite element plate type, with a $1 \mathrm{~mm}$ objective meshing size (the FREM program has a meshing algorithm that uses triangular and quadrangular elements simultaneously to guarantee optimum quality mesh), as shown in the Appendix Figure A5, The partition was considered embedded in the upper and lower floors.

Perfect adhesion was assumed between the ceramic pieces and the joints' plaster adhesive material.

The joints acted as limiting surfaces of the final resilient capacity of the masonry.

Regarding the materials' mechanical behavior, they presented a diagram-tension linear elastic deformation until their strength was reached, after which point it is admitted that breakage occurs.

It is admitted that the rupture of the joint material occurs according to the Morh-Coulomb failure criterion [28].

The deformation did not affect the balance (Geometrically linear analysis) [29].

The equations resolution of the system was addressed by the NewtonRaphson method [30].

2.2.2.4. Results. In this section, the most relevant results obtained from the proposed partition analysis in the aforementioned conditions are presented. An iterative calculation was carried out, increasing the overload of use by $0.1 \mathrm{kN}$ each time until reaching the maximum overload of $1.5 \mathrm{kN}$, thus detecting the overload of use at which the cracking appears in the first place.

To realize the effect of the overloads of use on the one-sheet partition for the proposed system, horizontal loads of $0.35 \mathrm{kN} / \mathrm{m}, 0.4 \mathrm{kN} / \mathrm{m}, 0.45$ $\mathrm{kN} / \mathrm{m}, 0.80 \mathrm{kN} / \mathrm{m}$ and $1.5 \mathrm{kN} / \mathrm{m}$ were simulated. The results of these simulations were compared with the same progression of loads applied to a partition executed with conventional medium-format ceramic pieces (70 $507 \mathrm{~cm}$ ). For the proposed partition, the beginning of visible cracking occurred from $0.45 \mathrm{kN} / \mathrm{m}$ (Appendix Figure A6), while in the conventional partition this cracking became visible with a horizontal load of $0.35 \mathrm{kN} / \mathrm{m}$ (Appendix Figure A7). In both cases, the

Table 5

Materials partial safety coefficients, $\gamma$

\begin{tabular}{lllll}
\hline & \multicolumn{4}{l}{ Execution category } \\
\hline & & A & B & C \\
Production control category & I & 1,7 & 2,2 & 2,7 \\
& II & 2,0 & 2,5 & 3,0 \\
\hline
\end{tabular}

Table 6

Materials calculation strength.

\begin{tabular}{lll}
\hline & Cooked clay & Plaster adhesive material \\
\hline Compression strength $\left(\mathrm{N} / \mathrm{mm}^{2}\right)$ & 5,64 & 1,36 \\
Tensile strength $\left(\mathrm{N} / \mathrm{mm}^{2}\right)$ & 1,86 & 0.45 \\
\hline
\end{tabular}

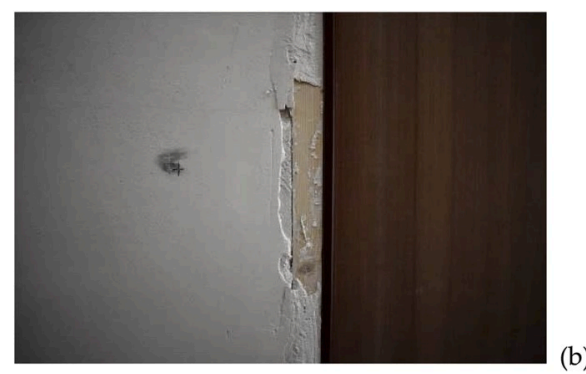

Fig. 11. Structural damages soft body impact test: (a) horizontal crack and (b) fissure with deformation in joint with the door frame. 
beginning of the cracking occurred at the base of the partition.

The horizontal displacements were magnified by a factor of 50 so that they could be visible. The non-linearity index shows the proportion of Gaussian points that were non-linearly analyzed at least once during the calculation process. Along with the criterion of tearing the material, the colors represent different damage states: Red, totally fissured areas; Green, partially fissured areas, and Blue, unfissured areas.

The simulations results for horizontal loads of 0.8 and $1.5 \mathrm{kN} / \mathrm{m}$ for both the proposed system and the conventional medium-sized ceramic solution are described below. The images show the effects of the applied load and its repercussion at different partition heights.

In the first two simulations, the effect of the application of $0.80 \mathrm{kN} / \mathrm{m}$ and $1.50 \mathrm{kN} / \mathrm{m}$ horizontal loads to the proposed one-sheet partition system is shown. On the left, the effects on the base of the partition and on three other points coinciding with the joints between blocks are shown, while on the right, the global view of the partition specifying the deformation values in each analyzed joint is shown. This deformation has been augmented 50 times in the image since the resulting maximum deformation of $3.9 \mathrm{~mm}$ would be barely perceptible.

Regarding the maximum resulting deformation of the proposed onesheet partition system for $0.80 \mathrm{kN} / \mathrm{m}$ horizontal load is $3.9 \mathrm{~mm}$ is shown in Appendix Figure A8b. Fissures are seen on the base and in the different joints analyzed, but the global stability of the partition is not compromised (Appendix Figure A8a).

With respect to the maximum resulting deformation of the proposed one-sheet partition system for $1.50 \mathrm{kN} / \mathrm{m}$ horizontal load is $10.6 \mathrm{~mm}$ (Appendix Figure A9b). Fissures are seen on the base and in the different joints analyzed, in this case, the global stability of the partition is compromised (Appendix Figure A9a).

Concerning the one-sheet conventional partition system for $0,80 \mathrm{kN} /$ $\mathrm{m}$ and for $1,50 \mathrm{kN} / \mathrm{m}$ the effects of the application of horizontal loads are shown in Appendix Figures A10 and A11. As in the previous case, the effects on the base of the partition and on three other points coinciding with the joints between blocks are shown on the left, while on the right, the global view of the partition specifying the deformation values in each analyzed joint is shown. As observed in the previous image, the maximum resulting deformation of the one-sheet conventional partition system for $0.80 \mathrm{kN} / \mathrm{m}$ horizontal load is $2.24 \mathrm{~mm}$ (Figure A10b), while for $1.50 \mathrm{kN} / \mathrm{m}$ horizontal load it is $7.31 \mathrm{~mm}$ (Figure A11b). In both cases, the global stability of the partition is compromised, with fissures affecting the entire base for both $0.80 \mathrm{kN} / \mathrm{m}$ horizontal loads (Fig. A10a) and $1.50 \mathrm{kN} / \mathrm{m}$ horizontal loads (Figure A11a) observed.

Regarding the second system configuration: For the two-detachedsheet partitions ( $40 \mathrm{~mm}$ gap between them), the same horizontal loads were simulated in order to perform the effect of the overloads of use. In this case, for the values of the overload studied in simple partitions ( 0.4 $\mathrm{kN} / \mathrm{m}, 0.8 \mathrm{kN} / \mathrm{m}$ and $1.5 \mathrm{kN} / \mathrm{m}$ ) it was observed that, even for the largest of them, the two sheets do not come into contact (maximum viable displacement $3.9 \mathrm{~mm}$ versus a gap of $40 \mathrm{~mm}$ ), so there was no interaction between them. When the partition received the horizontal action, it was only the sheet on which the force directly impacted that supported the overload. Therefore, what is said for simple partitions is applicable.

With respect to the third configuration: For the two-linked-sheet partitions (40 mm gap between them), it was admitted that both sheets were linked together by an appropriate number of keys. In this case, Spanish regulation CTE DB-SE-F, article 5.5 [31], establishes that "the horizontal action is distributed proportionally to the resistance to the lateral load that each sheet offers". In the study of the equal-sheet partitions, each one supported half the load.

In light of the simulations performed, it was concluded that: the proposed partition system presents acceptable mechanical behavior for overload values of up to:

a) One-sheet and two-detached-sheet partitions: $0.8 \mathrm{kN} / \mathrm{m}$

\section{b) Two-linked-sheet partition walls: $1.5 \mathrm{kN} / \mathrm{m}$}

Compared with partitions made with conventional blocks, it presents similar mechanical behavior, although it is noteworthy that the cracking begins in the new partition system with overload of use at a higher value than in the case of a conventional one.

The greater flexibility of the inner partition compared to the conventional one enables better behavior in the case of seismic action, which is an interesting feature for certain locations [32].

\subsection{Assessment of thermal performance}

According to Spanish thermal regulations [33] there are no thermal requirements for partition walls inside a dwelling or office. Therefore, it would not be necessary to assess the thermal performance of the wall built with the proposed system if its applicability was limited to a partition wall inside an independent zone. By contrast, when it comes to elements that are part of the building's thermal envelope or partition walls dividing heated from non-heated areas, it is necessary to comply with some minimum thermal performances. Therefore, since the proposed masonry system can be used to separate areas of different use and has an option designed for the building of the facades' inner sheet, these thermal requirements are applicable.

\subsubsection{Methodology}

In order to determine the validity of the proposed masonry system for use as internal facade sheet, a comparison was made between the new system and two of the most common construction solutions for this internal sheet: a ceramic brick masonry wall and a laminated gypsum panel wall. To avoid using thermal bridges as an internal facade sheet that would not specifically be required by the system, facade, an external wall insulation system (EWIS) was chosen in all three cases.

The thermal behavior of the system was considered on the basis of its overall heat transfer coefficient, or U-value (U). This coefficient is an indicator of the thermal transmittance of an element, including the heat transfer that occurs by conduction and radiation in the internal facade sheet, and by radiation and convection in the external facade sheet. As calculation data, the following values were taken: As indoor environmental conditions, those indicated in Spanish regulation CTE section 2.2 of DB HE [33], namely indoor temperature, $20 \mathrm{C}$, and indoor relative humidity, 55\%; As outdoor environmental conditions, those corresponding to the most demanding situation in terms of thermal insulation requirements in CTE Table C1 of Appendix of DB HE [33] were considered. These conditions correspond to climatic zone E (Burgos): Outdoor temperature, $2.6 \mathrm{C}$, and outdoor relative humidity, $86 \%$. Indoor and outdoor surface thermal resistance and air chamber resistance, Tables 1 and 2 respectively of the CTE DA DB HE [33], were also taken into account. For horizontal thermal flow calculations: Ris $0.25 \mathrm{~m}^{2}$ $\mathrm{K} / \mathrm{W}$ and Ros $0.04 \mathrm{~m}^{2} \mathrm{~K} / \mathrm{W}$. For thermal resistance of non-ventilated air chambers, the calculation program has an algorithm to calculate the equivalent thermal conductivity of the same, taking into account the direction of heat flow and temperature in each cycle; this procedure is based on European Standards EN ISO 6946 and EN ISO 10211:2012 [34]. The thermal and hygrometric characteristics of the materials of the homogenous layers of the analyzed systems are detailed below (Table 7).

The evaluation of thermal transport in building materials was carried out by different procedures, both experimentally and through simulations based on the intrinsic physical characteristics of the material [37]. Likewise, for the evaluation of the thermal behavior of masonry facade systems, in-situ standardized measurements methods can be applied to a prototype [38] or heat transfer simulations based on the characteristics of the different layers of the facades can be performed. In this study, the second of these procedures based on the finite element method (FEM) was applied. The FEM software package used for the calculation was BISCO, version 9.0w. Physibel c.v [39]. The reference tests proposed in EN ISO 10211:2012 [34] were followed in order to classify the software 
Table 7

Materials thermal and hygrometric characteristics.

\begin{tabular}{|c|c|c|c|c|}
\hline Material & $\begin{array}{l}\lambda(\mathrm{W} / \\
\mathrm{mK})\end{array}$ & $\mu$ & $\begin{array}{l}\text { Thickness } \\
\text { (m) }\end{array}$ & $\begin{array}{l}\text { Standard/ } \\
\text { Test }\end{array}$ \\
\hline Cement mortar & 1,3 & 10 & 0,015 & $\begin{array}{l}\text { CEC/CTE } \\
{[35]}\end{array}$ \\
\hline Perforated brick masonry & 0,49 & 10 & 0,115 & $\begin{array}{l}\text { CEC/CTE } \\
{[35]}\end{array}$ \\
\hline $\begin{array}{l}\text { Double hollow brick } \\
\text { masonry }\end{array}$ & 0,44 & 10 & 0,070 & $\begin{array}{l}\text { CEC/CTE } \\
{[35]}\end{array}$ \\
\hline Gypsum plaster & 0,57 & 6 & 0,015 & $\begin{array}{l}\text { CEC/CTE } \\
{[35]}\end{array}$ \\
\hline Polyurethane (PUR) & 0,028 & 105 & 0,080 & $\begin{array}{l}\text { CEC/CTE } \\
\text { [35] }\end{array}$ \\
\hline Proposed system masonry & $0,26^{\mathrm{a}}$ & $10^{\mathrm{b}}$ & 0,046 & Tested ${ }^{\mathrm{a}}$, \\
\hline $\begin{array}{l}\text { Expanded Polystyrene } \\
\text { (EPS) }\end{array}$ & 0,037 & 60 & 0,030 & $\begin{array}{l}\text { CEC/CTE } \\
{[35]}\end{array}$ \\
\hline
\end{tabular}

a Tested following the UNE EN ISO 8990:1997 standard [36].

b Assimilated to other analogous ceramic materials.

as a high-precision program (class A).

\subsubsection{Results}

Firstly, interstitial condensation of the three compared systems was verified: a ceramic brick masonry wall, the proposed masonry system wall, and a laminated gypsum panel wall. In no case did interstitial condensation appear (Fig. 12).

As can be observed in the previous graphs, the modification of the interior sheet of the facade involves hardly any variations with respect to the possible critical points in the analysis of interstitial condensation.

Secondly, the possible facade thermal bridges, specifically the two most representative (pillar-facade joints and edge-facade framework facade) were analyzed. The simulation graphic results for heat transfer through the facade at the connection with the pillars are shown below (Fig. 13).

The results analysis shows a slightly better performance in ceramic solutions for both the conventional and the proposed system, compared to the laminated gypsum panels. Despite this similarity of behavior, it is remarkable that the proposed system would require less facade thickness compared to conventional ceramic solutions.

Heat transfer pattern simulations at the connection of the edgefacade framework facade are shown below (Fig. 14). It is observed that the building's thermal cladding shows better behavior in the proposed solution than the conventional ones.

The numerical results of the simulations for both possible thermal bridges analyzed are shown above, (Table 8). All the thermal cladding systems studied are recommended for use in buildings located in climatic zones A to C, as specified in Spanish regulations [40], with a topographic altitude of less than $800 \mathrm{~m}$ above sea level. With the incorporation of the new masonry system, as the internal layer of a classic double-facade enclosure, not only are the thermal properties retained, but smaller enclosure thicknesses are also achieved. In neither situation did surface or interstitial condensation appear in the climatic data considered in the calculation.

\subsection{Evaluation of acoustic performance}

\subsubsection{Equipment and methodology}

The experimental procedure is described in UNE-EN ISO 10140-2:2011 [41]. The chambers where the test was carried out fulfil the requirements established in UNE EN ISO 10140-5: 2011 [42]. The chambers were horizontally adjacent, one of which, the left or receiving chamber, was fixed, and the other, the right or transmitting chamber, mobile. Both were shaped like an irregular prism with 6 sides, without parallel edges. The fixed or receiving chamber walls were composed of $30 \mathrm{~cm}$-thick concrete screens and internal acoustic tiles. The walls of the mobile or transmitting chamber walls were formed of $15 \mathrm{~cm}$-thick outer sandwich metal structures reinforced with acoustic absorbent and insulating materials, and internal acoustic flooring.

For this test, pink noise was generated from 2 source positions in the transmitting chamber. They were located at at least $0.7 \mathrm{~m}$ from the existing enclosures and on a tripod at different heights. For each source position, three measurements were made by means of a rotating microphone in the diffuse field area of the transmitting chamber. The microphone maintained a guaranteed minimum distance of $0.7 \mathrm{~m}$ from the walls of the test cell, $1 \mathrm{~m}$ from the sound source and $1 \mathrm{~m}$ from the sample being tested. The scanning radius of the microphone was $1 \mathrm{~m}$, with a minimum inclination of 10 . Meanwhile, for each source position, three measurements were made with a rotating microphone in the diffuse field area of the receiving chamber.

After, the background noise was measured in the receiving chamber with the sound source off. The time of each measurement was $48 \mathrm{~s}$ (3 full sweeps), enough time for the signal to stabilize. The measurements were made in each of the third-octave bands between 100 and $5000 \mathrm{~Hz}$. To measure the reverberation time, 2 source positions were used in the receiving chamber separated by more than $3 \mathrm{~m}$. For each source position, 3 microphone positions were used in the receiving chamber in order to measure reverberation. All were positioned more than $1 \mathrm{~m}$ from the side walls, $1.8 \mathrm{~m}$ between them and $2 \mathrm{~m}$ from the sound source. Two measurements were taken in each position and the respective mean values were obtained. The following instruments were used to perform the tests: Noise source, Brüel \& Kjaer type 4292, Pulse analyzer model B\&K 3560-B-030, Amplifier model PHONIC MAX 860, Equalizer in thirds of octave model dbx 131, Calibrator-verifier B\&K type 4231, class 1, Thermo-anemometer BARIGO, model No. 525, and two microphones model B\&K 4189.

Tests to determine acoustic performance were carried out on singleand double-partition designs. The single-sheet partition had a total thickness of $10 \mathrm{~cm}: 7 \mathrm{~cm}$ of the proposed block and a plaster coating of $1.5 \mathrm{~cm}$ on both sides. The two-sheet partition is regularly used to separate rooms for different use. Its total thickness was $21.5 \mathrm{~cm}$ : two 7 $\mathrm{cm}$ blocks, exterior $1.5 \mathrm{~cm}$ plaster coating on both sides and an internal $4.5 \mathrm{~cm}$ mineral wool insulation. The graphic description of both systems is presented in the previous construction details (Fig. 15). Pictures of the assembly process of both partition systems prior to performing the tests are shown below (Fig. 16).

\subsubsection{Test characteristics and conditions}

As previously mentioned, two partition systems were tested: Singlesheet partition and Two-sheet partition. The samples' drying time was two weeks. Once dried and ready to test, the samples were transferred to the corresponding test chambers. In the case of the single-sheet partition, the nominal thickness of the sample was $10 \mathrm{~cm}$ with an approximate surface mass of $82 \mathrm{~kg} / \mathrm{m}^{2}$; the two-sheet partition sample had a nominal thickness of $21.5 \mathrm{~cm}$ and an approximate surface mass of 134.4 $\mathrm{kg} / \mathrm{m}^{2}$.

The dimensions of the measurement opening for both cases were 3.6 $\mathrm{m}$ width by $2.8 \mathrm{~m}$ height, with total surface area of each sample measuring $10.08 \mathrm{~m} 2$. The volume of the transmitting chamber was $60.61 \mathrm{~m}^{3}$, and that of the receiving chamber was $50.76 \mathrm{~m}^{3}$. The transmitting chamber temperature was (19.5 0.3$)$ C, with relative humidity at (45.8 $\quad 0.3) \%$; static pressure was $947 \mathrm{hPa} \quad 0$. The receiving chamber temperature was $\left(\begin{array}{lll}19.3 & 0.1\end{array}\right) \quad \mathrm{C}$, with relative humidity at (45.7 0.3) \%; static pressure was (947 0 ) $\mathrm{hPa}$.

\subsubsection{Analysis of results}

2.4.3.1. Single-sheet partition. The following acoustic reduction parameters were obtained for the single-sheet partition: Fig. 17 presents the plotted values of the measured spectrum and the adjusted reference curve. Table 9 presents the 18 values of the reference curve, from $100 \mathrm{~Hz}$ to $5000 \mathrm{~Hz}$. From the results, it is possible to conclude that the airborne 

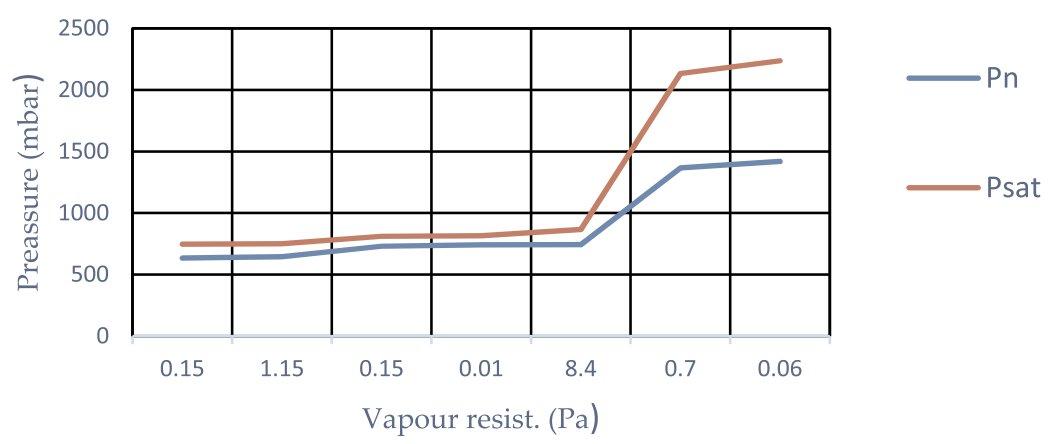

Ceramic brick masonry

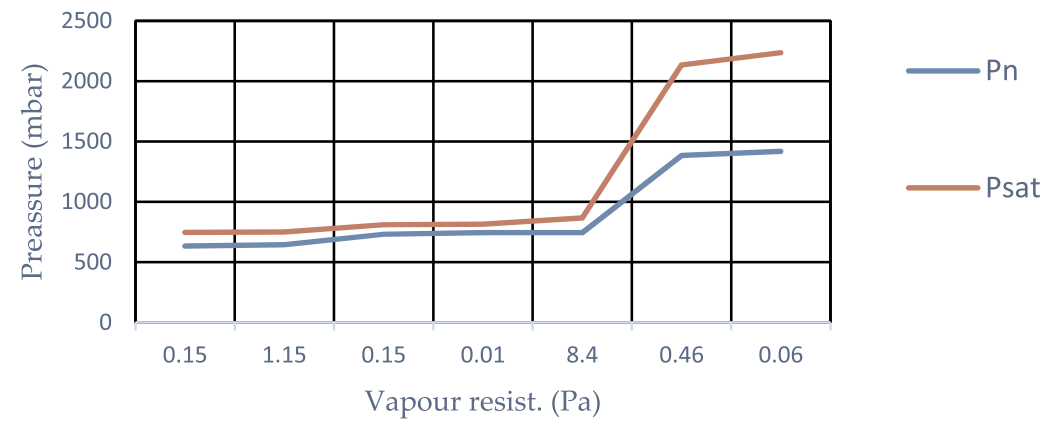

Proposed masonry system

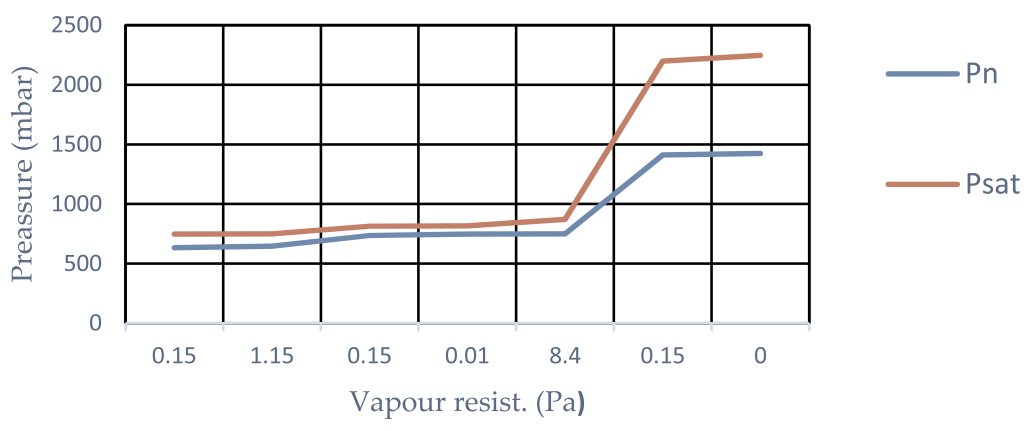

Laminated gypsum panels

Psat $=$ Water vapor saturation pressure $(\mathrm{Pa})$.

$\mathrm{Pn}=$ Water vapor pressure on the surface of each layer.

Fig. 12. Interstitial condensations comparison for the three systems analyzed.

sound reduction index for this wall measured about $35 \mathrm{~dB}$. This global sound insulation parameter was calculated according to ISO 717-1: 2013 [43] and was in line with Spanish acoustic regulation for buildings CTE DB-HR [44].

Since a conventional partition wall (horizontally perforated brick masonry of $11 \mathrm{~cm}$ thickness with cement mortar on both sides) has an estimated airborne sound reduction index ranging from 36.0 to $43.2 \mathrm{~dB}$ (39 $\mathrm{dB}$ average), it is possible to observe that the airborne sound reduction index of the proposed system is an average of $4 \mathrm{~dB}$ lower than the conventional solution, but suitable for partitions between rooms of similar use, as is the case of those inside a house (see Fig. 17 and Table 9).
2.4.3.2. Two-sheet partition. The following acoustic reduction parameters were obtained for the two-sheet partition: Fig. 18 presents the plotted values of the measured spectrum and the adjusted reference curve. Table 10 presents the 18 values of the reference curve, from 100 $\mathrm{Hz}$ to $5000 \mathrm{~Hz}$. From the results, it is possible to conclude that the airborne sound reduction index for this wall measured about $58.5 \mathrm{~dB}$. This global sound insulation parameter was calculated according to ISO 717-1: 2013 [35] and was in line with Spanish acoustic regulation for buildings CTE DB-HR [36].

These results indicate that, according to Spanish acoustic regulation for buildings CTE BD-HR [36], this technology can be used, for instance, in walls separating two rooms of different dwellings (DnT, wP $50 \mathrm{~dB}$ ) or 


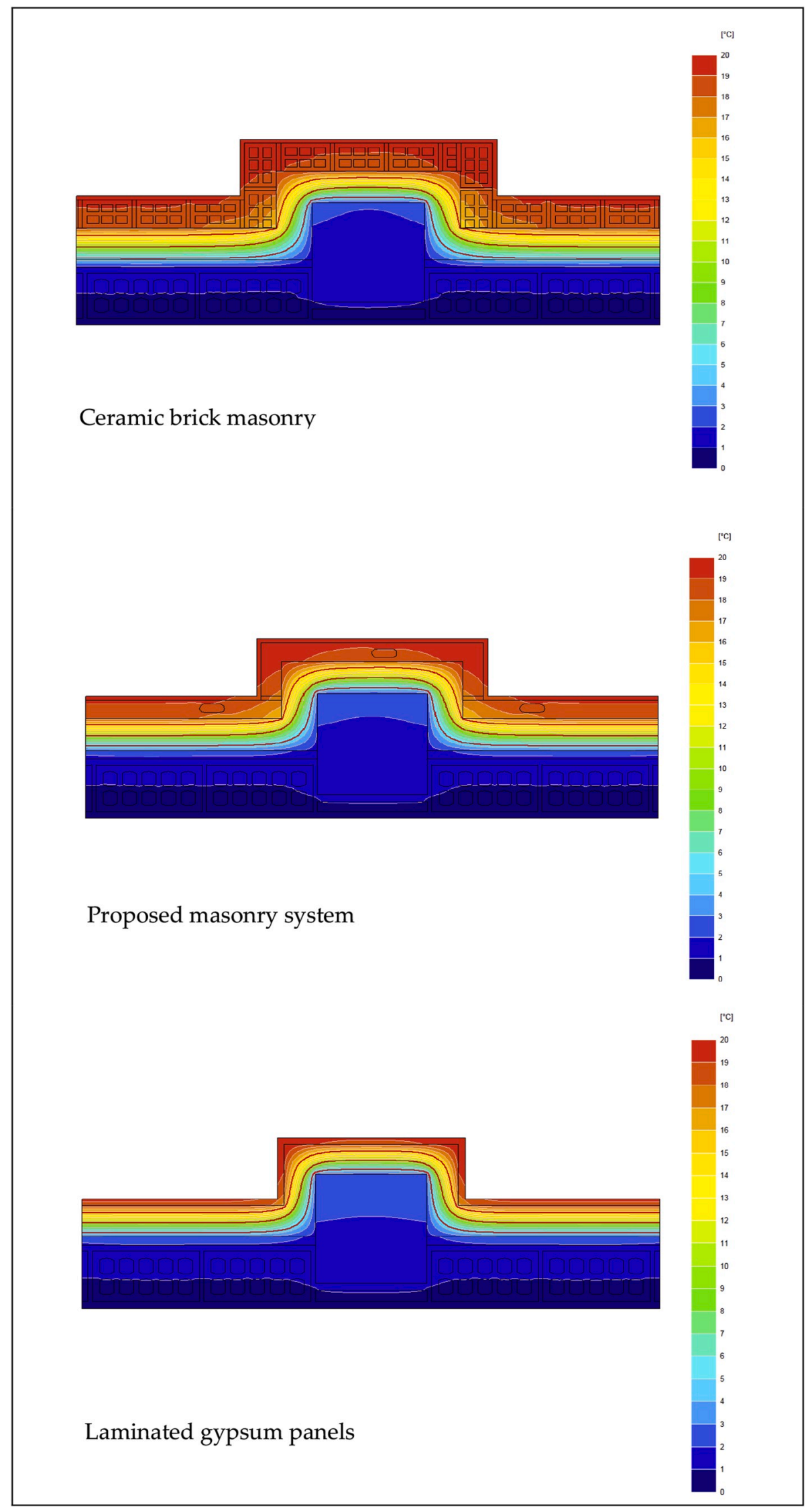

Fig. 13. Heat transfer patterns through the façade at the connection with pillars for the three systems analyzed. 


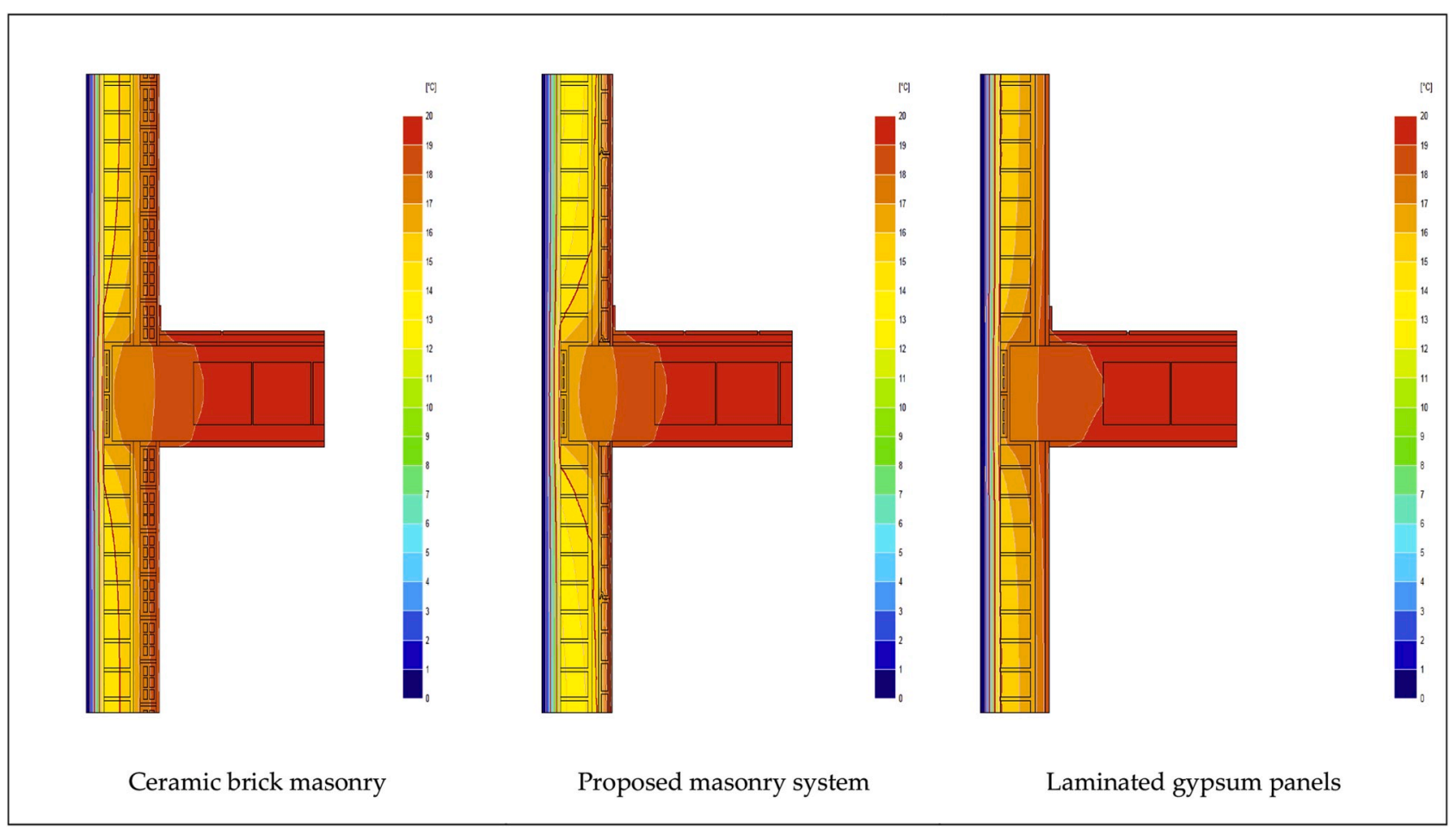

Fig. 14. Heat transfer patterns through the façade at the connection with framework edges for the three systems analyzed.

Table 8

Summary of thermal simulation results.

\begin{tabular}{|c|c|c|c|c|c|}
\hline \multirow[t]{2}{*}{ System } & \multirow[t]{2}{*}{ Thickness (cm) } & \multirow{2}{*}{$\begin{array}{l}\text { Transmittance } \\
\mathrm{U}\left(\mathrm{W} / \mathrm{m}^{2} \mathrm{~K}\right)\end{array}$} & \multicolumn{2}{|l|}{ Thermal bridges } & \multirow[t]{2}{*}{ Recommended CTE DB HE [27] } \\
\hline & & & Pillars $\left(\mathrm{W} / \mathrm{m}^{2} \mathrm{~K}\right)$ & Framework edge $\left(\mathrm{W} / \mathrm{m}^{2} \mathrm{~K}\right)$ & \\
\hline Ceramic brick masonry & 31,5 & 0,415 & 0,162 & 0,156 & $\begin{array}{l}\text { Climate zone C } \\
0,27<U<0,29\end{array}$ \\
\hline Proposed masonry system & 29,1 & 0,412 & 0,177 & 0,166 & $\begin{array}{l}\text { Climate zone C } \\
0,27<U<0,29\end{array}$ \\
\hline Laminated gypsum panels & 26,0 & 0,435 & 0,144 & 0,166 & $\begin{array}{l}\text { Climate zone } \mathrm{C} \\
0,27<\mathrm{U}<0,29\end{array}$ \\
\hline
\end{tabular}

in walls separating one room from common circulation areas (DnT, wP $48 \mathrm{~dB}$ ). (see Fig. 18 and Table 10).

\section{Discussion}

From the results provided in this paper, the following statements can be made:

The geometry of the blocks was designed so that vertical and horizontal perforation was possible to allow the placement of installations. From the construction of a real prototype wall under in situ conditions, it was possible to assess the adequate design of the blocks that facilitate the introduction of facilities.

The construction technology is a phased process to allow the addition of two lateral punctures perpendicular to the extrusion direction to facilitate the placement of facilities without negatively impacting the modelling and cooking of the blocks.

The solution demonstrated good behavior for impact loads, in both hard- and soft-body impact loads, satisfying all the resistance requirements in European regulations.

For the selected category of use, it was seen that the wall exhibits good performance for eccentric loads, capable of supporting low to moderate levels of eccentric loads.
Mechanical simulations using finite element methodology also revealed the high stability of the proposed masonry systems. Furthermore, compared with partitions made with conventional blocks and in spite of the fact that presents similar mechanical behavior, it is noteworthy that the cracking begins in the new partition system with overload of use at a higher value than in the case of a conventional one. This greater flexibility of the inner partition compared to the conventional one enables better behavior in the case of seismic action.

The thermal performance of the proposed cladding systems can be recommended for use in buildings located in climatic zones A to $\mathrm{C}$ defined in Spanish regulations [32], with a topographic altitude of less than $800 \mathrm{~m}$ above sea level. The system is better than the traditional solution based on horizontally perforated brick masonry, and comparable to prefabricated plasterboard systems in the solution of the main thermal bridges.

Regarding acoustic performance, the single-sheet partition presented an airborne sound reduction index for this wall of about $35 \mathrm{~dB}$, which is suitable for the use of partitions between rooms used in a similar way, while the two-sheet partition presented an airborne sound reduction index for this wall of about $58.5 \mathrm{~dB}$ which, according to Spanish acoustic regulation for buildings CTE BD-HR [36], would allow this system to be used in walls separating two rooms of different dwellings (DnT, wP 50 


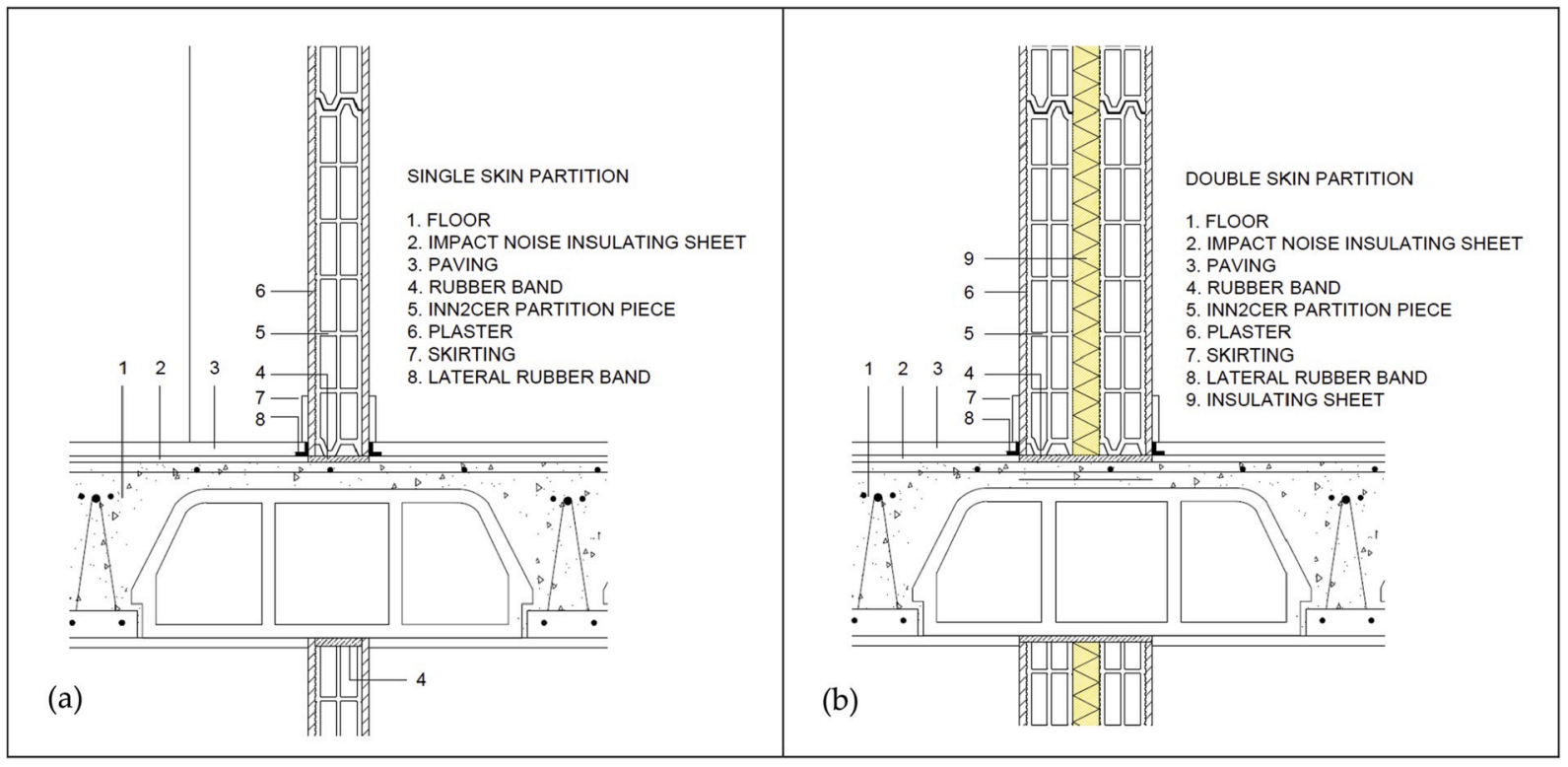

Fig. 15. Constructive details of the partitions tested to determine their acoustic performance.

ingle-sheet partition and (b) two-sheet partition.
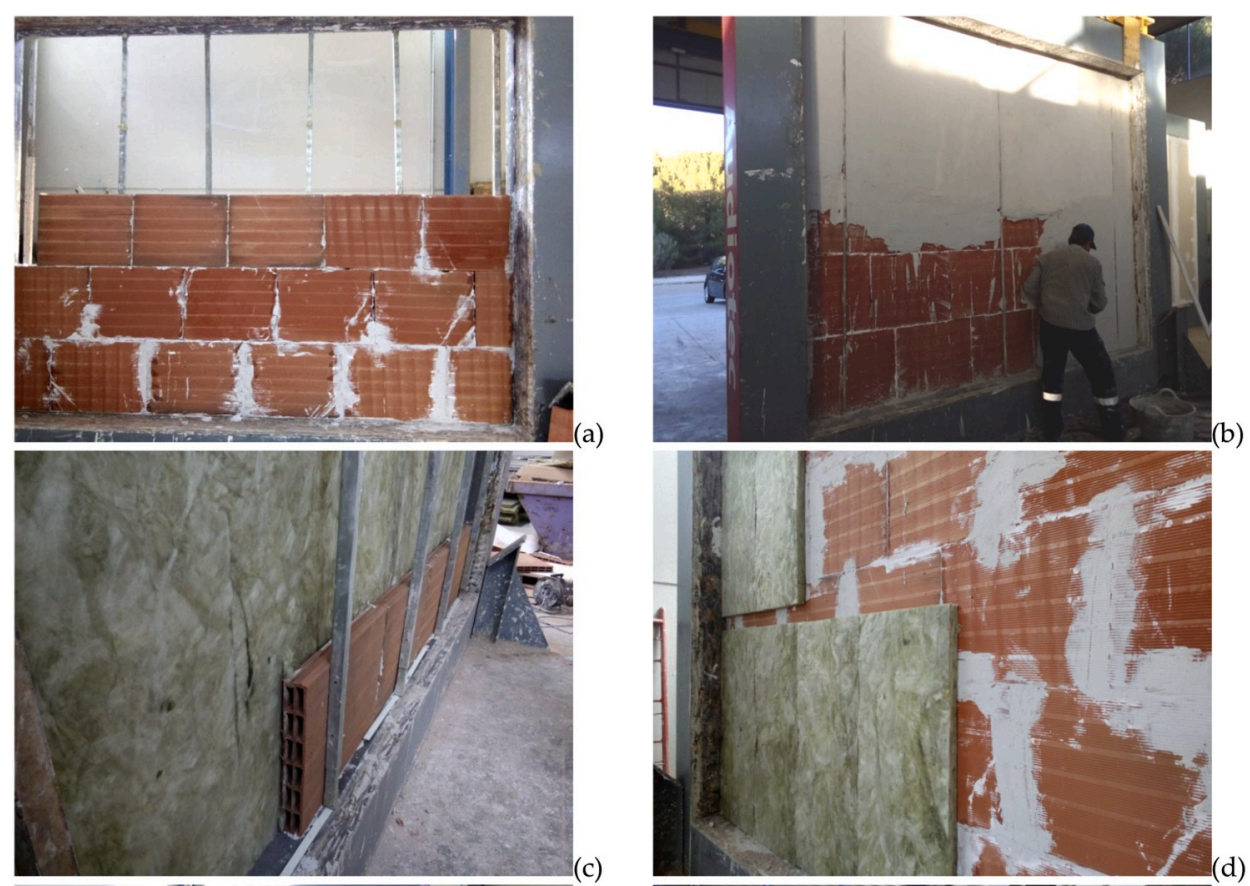

(b)
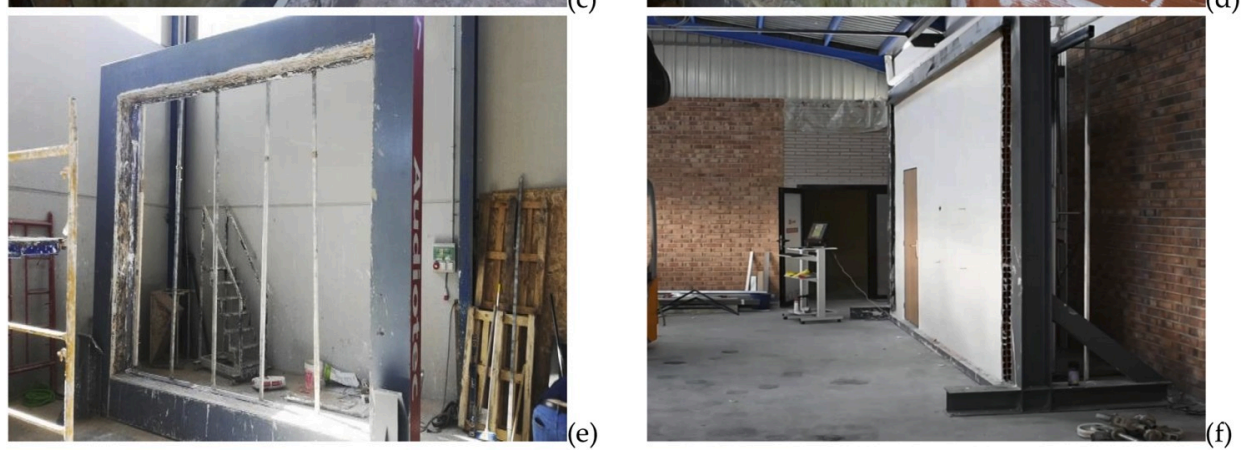

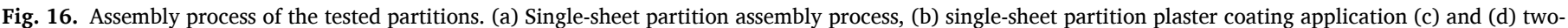
sheet partition insulation panel assembly, (e) perimeter frame for testing both partitions and (f) executed partition feature. 


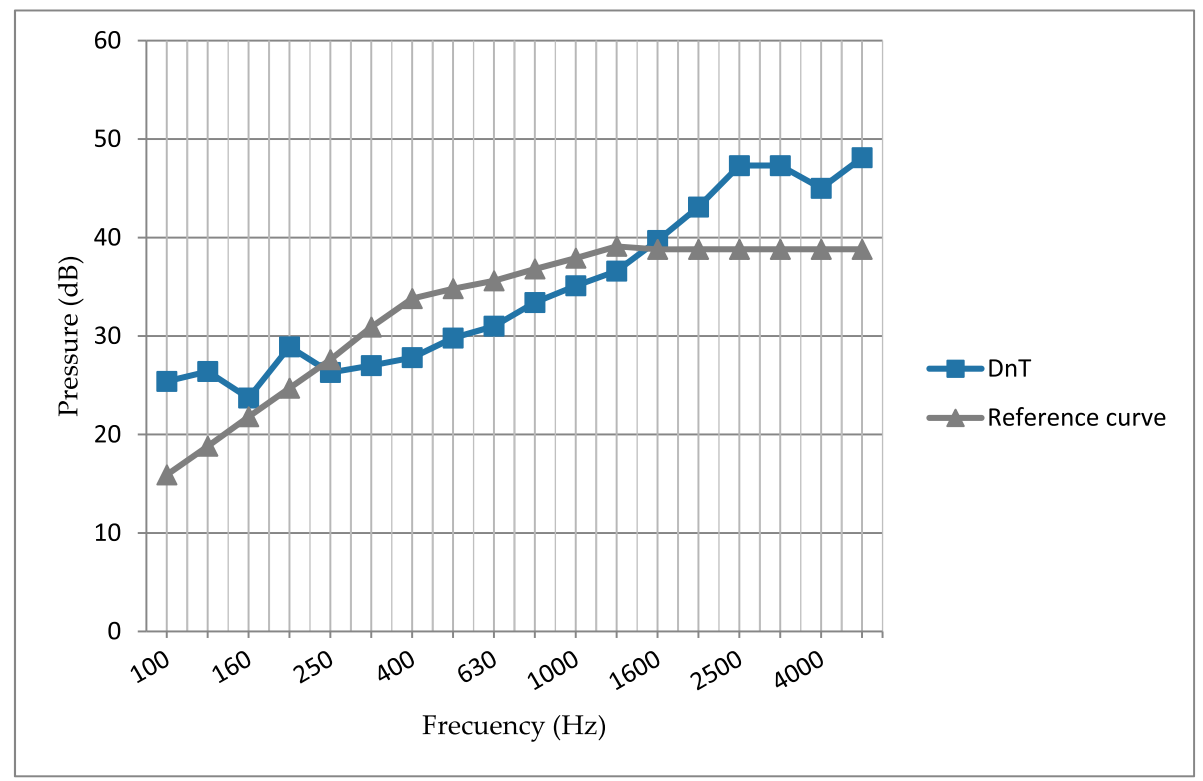

Fig. 17. Measured spectrum of the Standardized Sound Level Difference (DnT) and the adjusted reference curve for the single-sheet partition.

Table 9

Standardized sound level difference (DnT) for the single-sheet partition.

\begin{tabular}{|c|c|c|c|c|c|c|c|c|c|c|c|c|c|c|c|c|c|c|}
\hline Frequency $(\mathrm{Hz})$ & 100 & 125 & 160 & 200 & 250 & 315 & 400 & 500 & 630 & 800 & 1000 & 1250 & 1600 & 2000 & 2500 & 3150 & 4000 & 5000 \\
\hline DnT (dB) & 24,4 & 26,4 & 23,7 & 28,9 & 26,3 & 27,0 & 27,8 & 29,8 & 31,0 & 33,4 & 35,1 & 36,6 & 39,7 & 43,1 & 47,3 & 47,3 & 45,0 & 48,1 \\
\hline
\end{tabular}

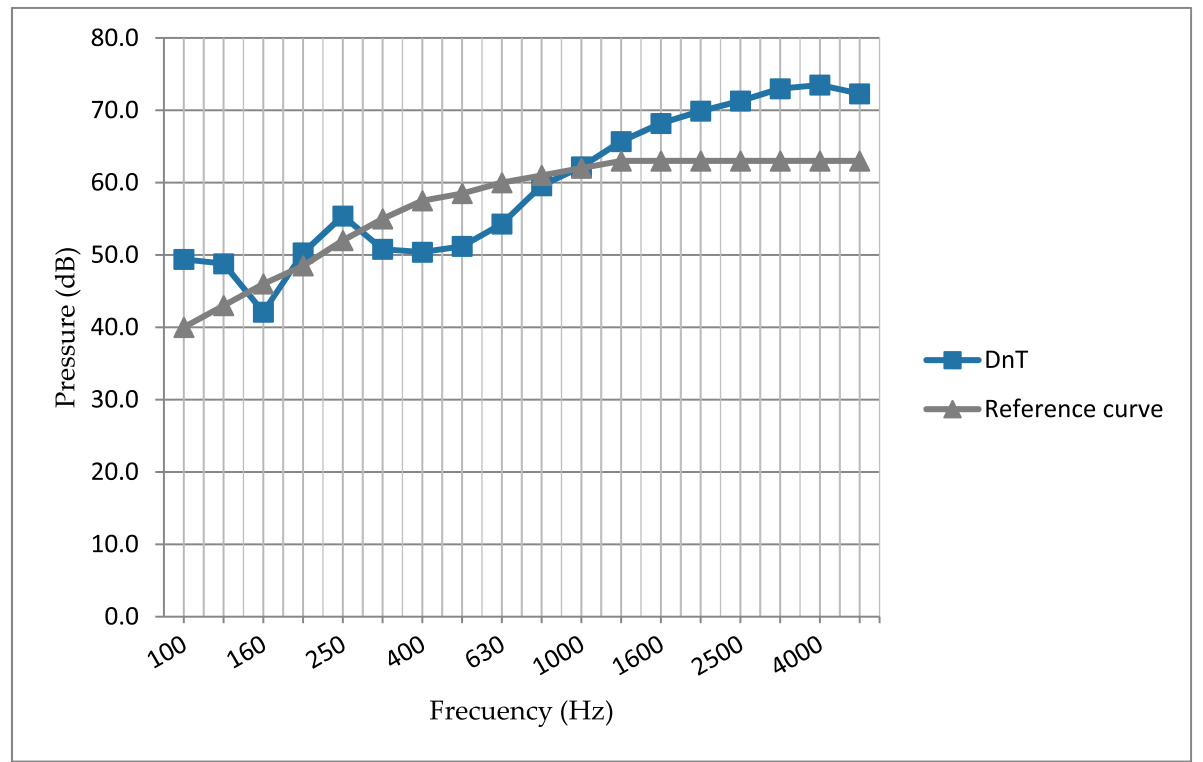

Fig. 18. Measured spectrum of the Standardized Sound Level Difference (DnT) and the adjusted reference curve for the two-sheet partition.

$\mathrm{dB})$ or in walls separating one room from common circulation areas (DnT, wP $48 \mathrm{~dB}$ ).

\section{Conclusions}

The work presented in this paper proposes a novel ceramic solution for partition and internal facade sheet masonry walls that allows for the integration of facilities with a minimum generation of waste. The work encompassed the following steps: (1) definition of the geometry of the blocks and system design; (2) production process and technology of the blocks; (3) validation of the masonry mechanical behavior; and (4) assessment of the thermal and acoustic performances of the proposed solution.

Overall, based on the analysis of results of the assessment of the 
multi-functional performance of the proposed systems, it should be said that the main advantages of this innovative construction technology, in relation to other existing solutions for partition walls made of hollow brick units or medium-sized ceramic blocks, are, on the one hand, that the technology described allows for the placement of facilities while generating hardly any waste, assuming that it would hardly be necessary to carry out on-site drilling of the partitions in the case of flexible electricity and plumbing installations, and with minimum on-site drilling in the case of installations carried out with rigid pipe systems. And, on the other hand, that this innovative system not only reduces execution times thanks to its facilities integration design, but it also matches or even improves the conditions of mechanical stability and thermal and acoustic transmissions compared to other conventional partition systems.

Concerning the generation of waste, despite difficulties in obtaining statistics about the exact amount of waste due to on-site breakdowns for the inclusion of installations in architectural partitions, these data can be inferred from different sources. On the one hand, the Environmental Product Declarations (EPD) for clay construction products [45] based on UNE-EN ISO 14025:2010 [46] which states that the losses in the construction of masonry partitioning reach up to $3 \%$. This percentage also includes breaks and leftovers during execution. These values, translated into large-format blocks in $\mathrm{kg} / \mathrm{m}^{2}$ are equivalent to $1.40 \mathrm{~kg} / \mathrm{m}^{2}$ of waste. On the other hand, using the database of CYPE's commercial price generator software [47], it is possible to have an estimation of waste per linear meter of channel openings for installations inside masonry partitioning. This database is more specific, since it includes the waste generated by channel opening-and-closing procedures for ceramics, mortars and packaging. In the case of ceramics, these residues can reach up to $0,901 \mathrm{~kg} / \mathrm{m}$, in the case of mortars up to $0,446 \mathrm{~kg} / \mathrm{m}$ and, in the case of packaging (plastic, wood and cardboard) up to $1,447 \mathrm{~kg} / \mathrm{m}$. This waste would be reduced to almost zero with the use of the proposed system in the case of flexible electrical installations and by a large percentage in the case of rigid plumbing installations.

\section{Declaration of competing interest}

Please check the following as appropriate:

- All authors have participated in (a) conception and design, or analysis and interpretation of the data; (b) drafting the article or revising it critically for important intellectual content; and (c) approval of the final version.

- This manuscript has not been submitted to, nor is under review at, another journal or other publishing venue.

- The authors have no affiliation with any organization with a direct or indirect financial interest in the subject matter discussed in the manuscript

- The following authors have affiliations with organizations with direct or indirect financial interest in the subject matter discussed in the manuscript:

\section{Acknowledgments}

The authors would like to sincerely thank the financial support of this work in the scope of the research Project INN2CER, Industrializacion de Innovadores Cerramientos Ceramicos, with reference number P/12/TEP-1923 of the 2016 call of the Direccion General de Investigacion, Tecnología y Empresa. Consejería de Economía, Innovacion, Ciencia y Empleo. Junta de Andalucia. 


\section{Appendix}
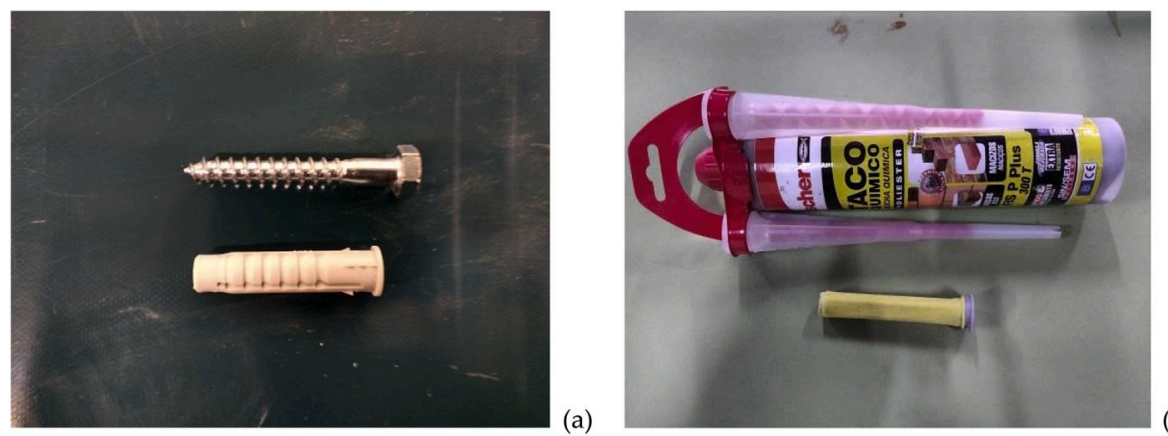

(b)

Fig. A.1. (a) Category A: mechanical anchoring elements. And (b) Category B: chemical anchoring elements.

Table A.1

Structural damages, vertical eccentric load results (Category A)

\begin{tabular}{llcc}
\hline Structural damages & Anchoring damages & Maximum deflection (mm) & Residual deflection (mm) \\
\hline Not observed & Not observed & 0,25 & 0,10 \\
\hline
\end{tabular}

Table A.2

Functional damages, vertical eccentric load results (Category B)

\begin{tabular}{|c|c|c|c|c|c|}
\hline Cycle & Transverse deformation (mm) & Cycle & Transverse deformation (mm) & Cycle & Transverse deformation (mm) \\
\hline 1 & 1.75 & 11 & 1.80 & 21 & 1.80 \\
\hline 2 & 1.70 & 12 & 1.80 & 22 & 1.85 \\
\hline 3 & 1.70 & 13 & 1.80 & 23 & 1.85 \\
\hline 4 & 1.70 & 14 & 1.75 & 24 & 1.85 \\
\hline 5 & 1.75 & 15 & 1.80 & 25 & 1.85 \\
\hline 6 & 1.75 & 16 & 1.80 & 26 & 1.85 \\
\hline 7 & 1.75 & 17 & 1.85 & 27 & 1.85 \\
\hline 8 & 1.75 & 18 & 1.80 & 28 & 1.80 \\
\hline 9 & 1.75 & 19 & 1.85 & 29 & 1.80 \\
\hline 10 & 1.80 & 20 & 1.85 & 30 & 1.80 \\
\hline
\end{tabular}

Table A.3

Rigid body impact results (Category III).

\begin{tabular}{|c|c|c|c|c|c|}
\hline \multicolumn{6}{|c|}{ Functional damages } \\
\hline Impact & Impact height (m) & Trace diameter $(\mathrm{mm})$ & Fissured trace $(\%)^{1}$ & Trace depth (mm) & Remarks \\
\hline D4 (1) & 1,20 & 25,30 & $* 25 \%$ & 3,10 & No other damage is observed in the sample \\
\hline D4 (2) & 1,20 & 24,20 & Faultless & 3,30 & \\
\hline D4 (3) & 1,20 & 23,70 & Faultless & 2,90 & \\
\hline D4 (4) & 1,20 & 20,40 & $* * 18 \%$ & 2,20 & \\
\hline D4 (5) & 1,20 & 21,40 & Faultless & 2,30 & \\
\hline D4 (6) & 1,20 & 23,50 & Faultless & 2,90 & \\
\hline D4 (7) & 1,20 & 26,80 & Faultless & 3,80 & \\
\hline D4 (8) & 1,20 & 24,50 & $* * 45 \%$ & 3,10 & \\
\hline D4 (9) & 1,20 & 21,70 & Faultless & 2,60 & \\
\hline D4 (10) & 1,20 & 20,90 & $* * 25 \%$ & 2,10 & \\
\hline D4 (11) & 1,80 & 24,90 & Faultless & 3,20 & \\
\hline D4 (12) & 1,80 & 22,30 & Faultless & 2,50 & \\
\hline D4 (13) & 1,80 & 20,60 & Faultless & 2,20 & \\
\hline D4 (14) & 1,80 & 20,20 & Faultless & 2,70 & \\
\hline D4 (15) & 1,80 & 21,20 & Faultless & 2,40 & \\
\hline D4 (16) & 1,80 & 21,10 & Faultless & 2,30 & \\
\hline D4 (17) & 1,80 & 20,70 & Faultless & 2,35 & \\
\hline D4 (18) & 1,80 & 20,30 & Faultless & 2,20 & \\
\hline D4 (19) & 1,80 & 19,30 & Faultless & 2,00 & \\
\hline D4 (20) & 1,80 & 18,20 & $* 10 \%$ & 1,80 & \\
\hline \multicolumn{6}{|c|}{ Structural damages } \\
\hline D2 (1) & 1,60 & 24,60 & $* * 70 \%$ & 2,60 & No other damage is observed in the sample \\
\hline
\end{tabular}


Table A.3 (continued)

\begin{tabular}{|c|c|c|c|c|c|}
\hline \multicolumn{6}{|c|}{ Functional damages } \\
\hline Impact & Impact height (m) & Trace diameter $(\mathrm{mm})$ & Fissured trace $(\%)^{1}$ & Trace depth (mm) & Remarks \\
\hline D2 (2) & 1,60 & 25,20 & * $10 \%$ & 2,70 & \\
\hline D3 (1) & 1,40 & 24,70 & $* * 20 \%$ & 2,60 & \\
\hline D3 (2) & 1,40 & 23,30 & $* * 60 \%$ & 2,20 & \\
\hline
\end{tabular}

${ }^{1}$ Approximate values.

* Chipped surface in the impact trace.

** Microcracks on the impact perimeter trace.

Table A.4

Functional damages soft body impact test (Categories II to IV).

\begin{tabular}{|c|c|c|c|c|c|}
\hline Series & Impact & Power (Nm) & Max. deflection. (mm) & Residual deformation (mm) & Remarks \\
\hline \multirow[t]{3}{*}{ B4 (Series 2) } & 1 & 120 & 5,45 & 0,50 & \multirow{3}{*}{$\begin{array}{l}\text { Horizontal crack impact } 2 \\
\text { Plaster release impact } 3 .\end{array}$} \\
\hline & 2 & 120 & 8,05 & 0,55 & \\
\hline & 3 & 120 & 9,80 & 1,50 & \\
\hline \multirow[t]{3}{*}{ B4 (Series 1) } & 1 & 120 & 6,25 & 0,10 & \multirow[t]{6}{*}{ Plaster release impact 1.} \\
\hline & 2 & 120 & 6,00 & 0,40 & \\
\hline & 3 & 120 & 7,45 & 1,40 & \\
\hline \multirow[t]{3}{*}{ B4 (Series 3) } & 1 & 120 & 5,70 & 0,80 & \\
\hline & 2 & 120 & 4,80 & 1,30 & \\
\hline & 3 & 120 & 5,05 & 3,05 & \\
\hline
\end{tabular}

Table A.5

Structural damages soft body impact test (Category III).

\begin{tabular}{|c|c|c|c|}
\hline Series & Max. deflection. (mm) & Residual deformation (mm) & Remarks \\
\hline B5 & 15,30 & 3,15 & $\begin{array}{l}\text { The horizontal crack appeared in B4 (Series 2) increases, (Fig. } 12 \text { a). } \\
\text { A fissure with deformation in joint with door frame is generated, (Fig. } 12 \text { b). }\end{array}$ \\
\hline
\end{tabular}

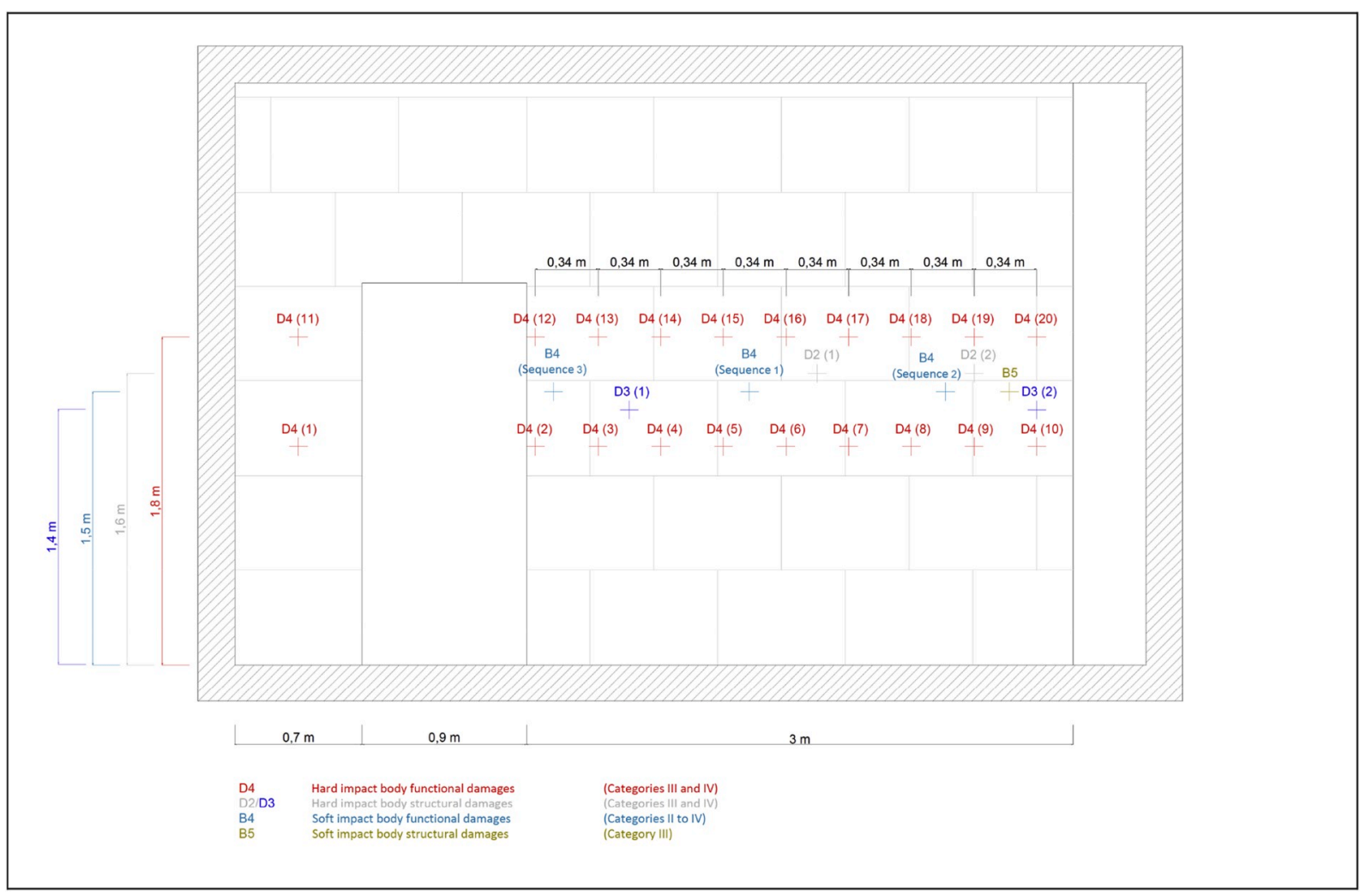

Fig. A.2. Impact test diagram. 


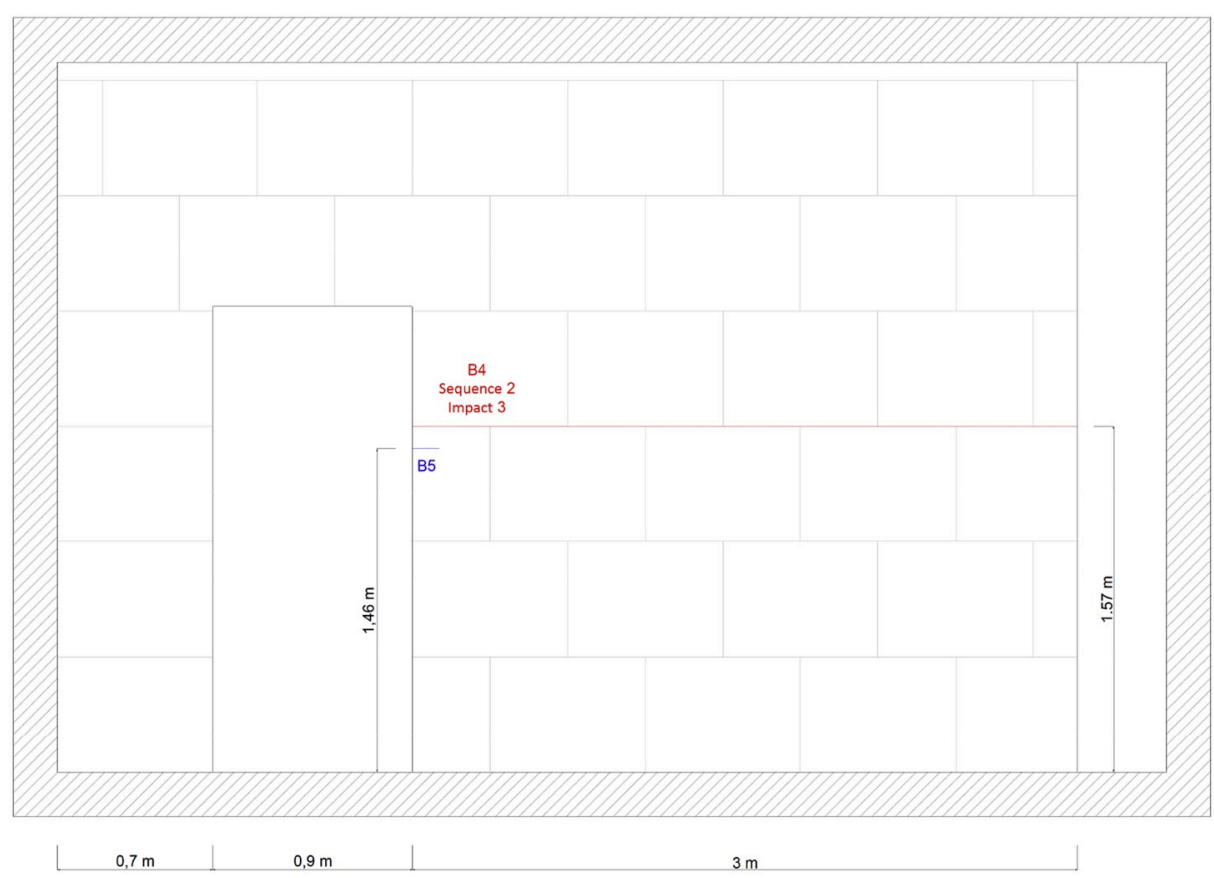

\section{- Fissure Fissure with deformation}

Fig. A.3. Resulting damages on the partition front side after the impact test.

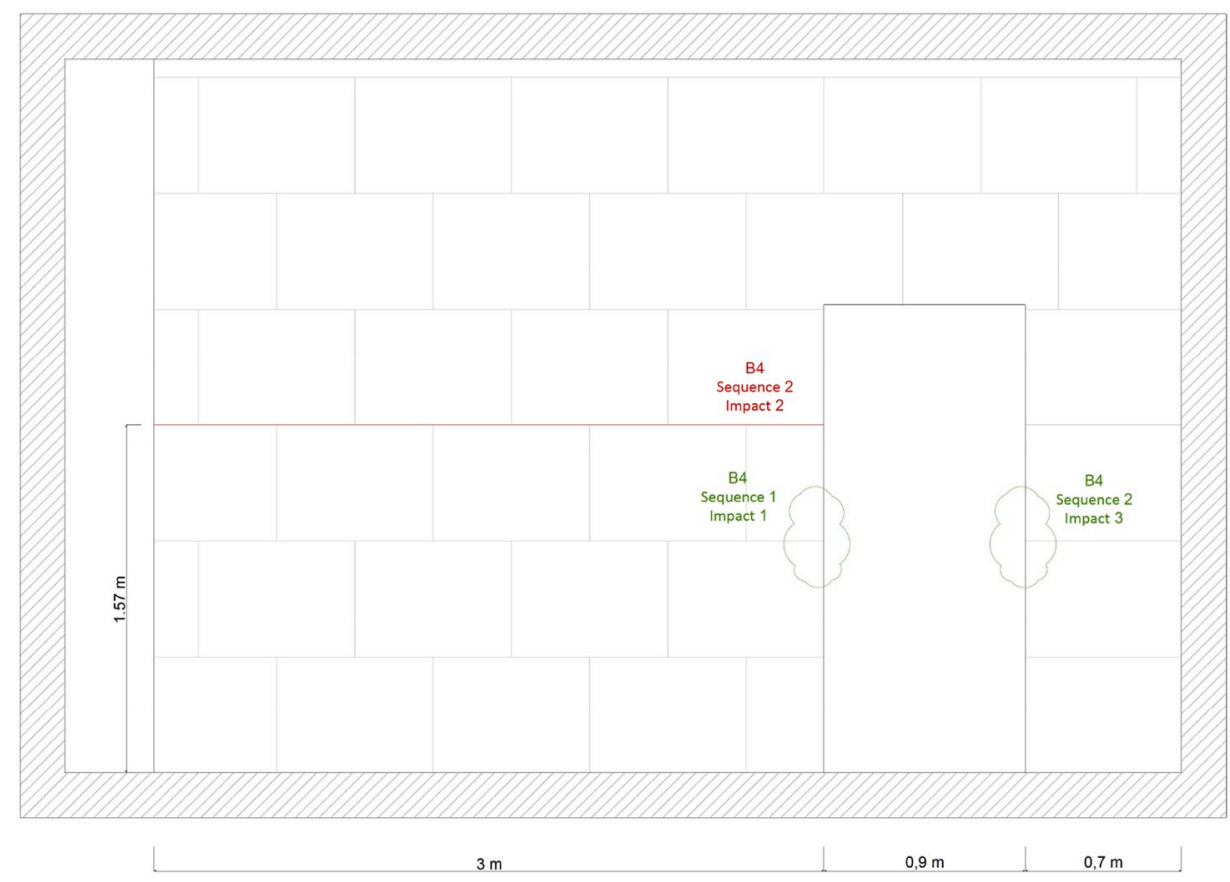

Fissure Fissure with deformation Plaster detachment

Fig. A.4. Resulting damages on the partition backside after the impact test. 


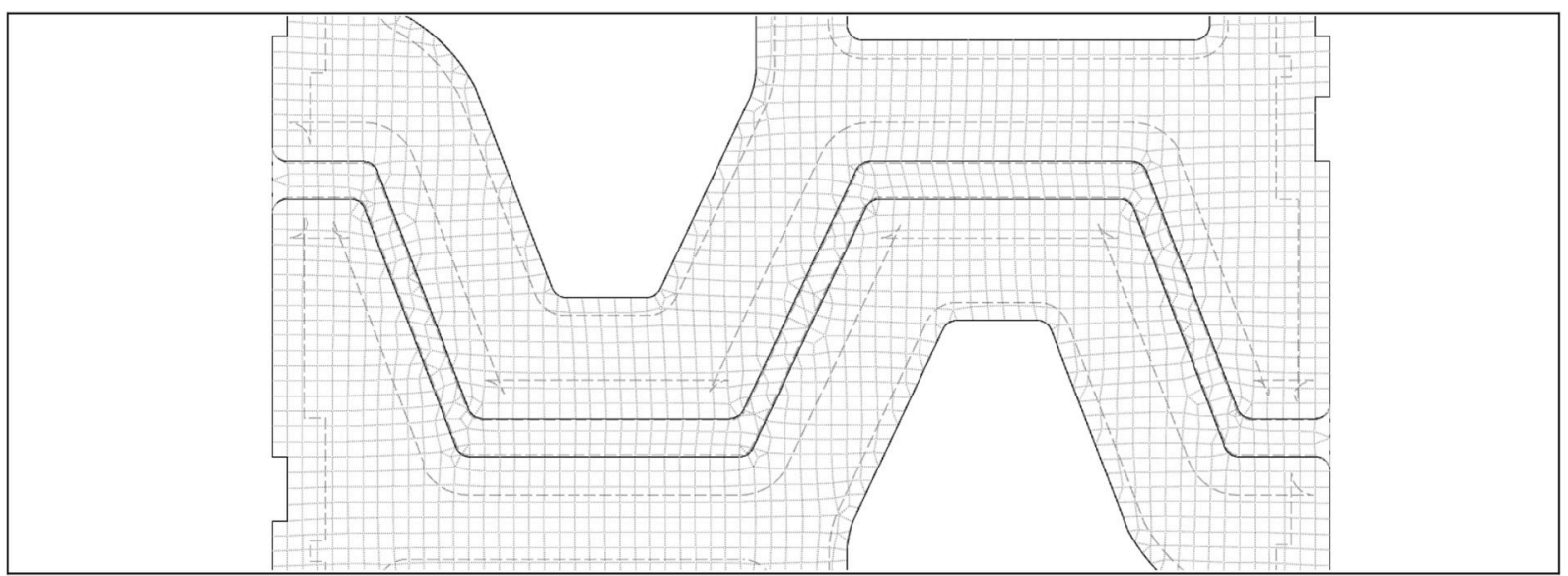

Fig. A.5. Mesh detail.

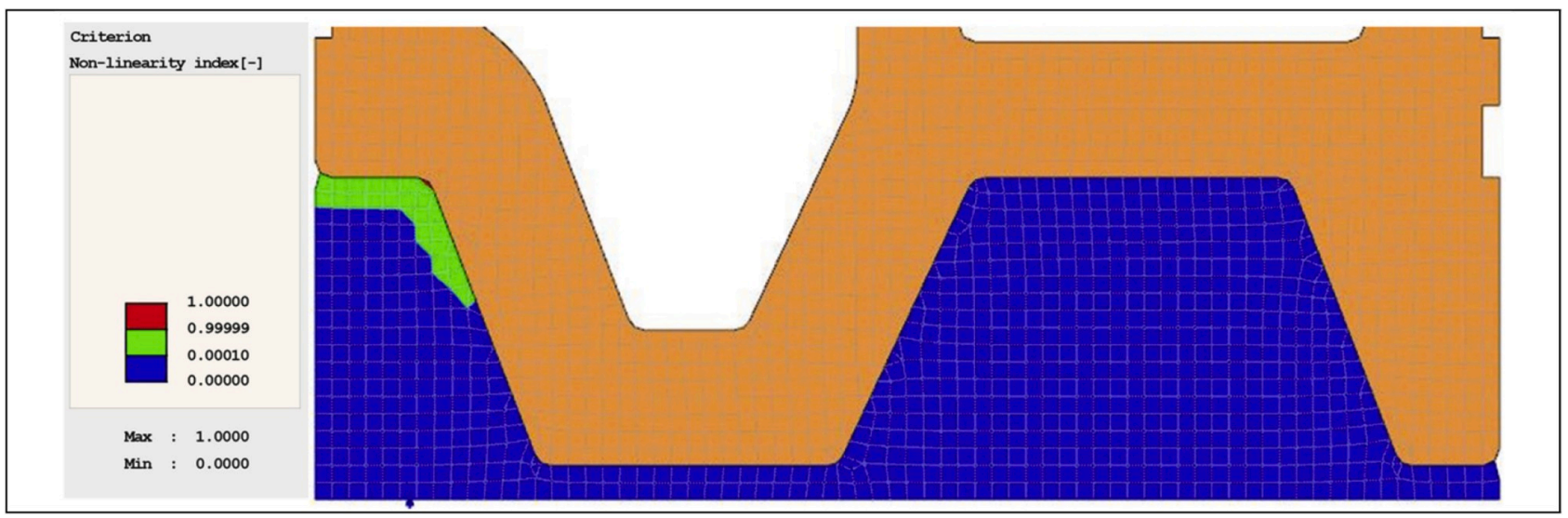

Fig. A.6. Fissure at the base of the one-sheet proposed partition for $0.45 \mathrm{kN} / \mathrm{m}$ horizontal load.

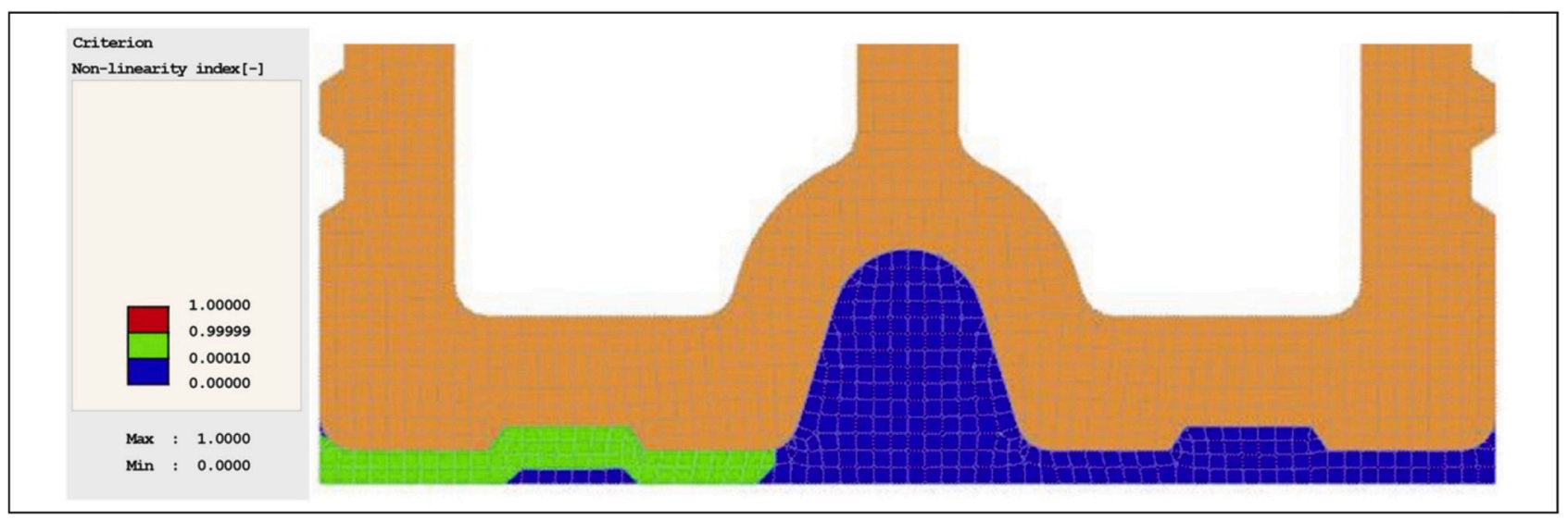

Fig. A.7. Fissure at the base of the one-sheet conventional partition for $0.35 \mathrm{kN} / \mathrm{m}$ horizontal load. 


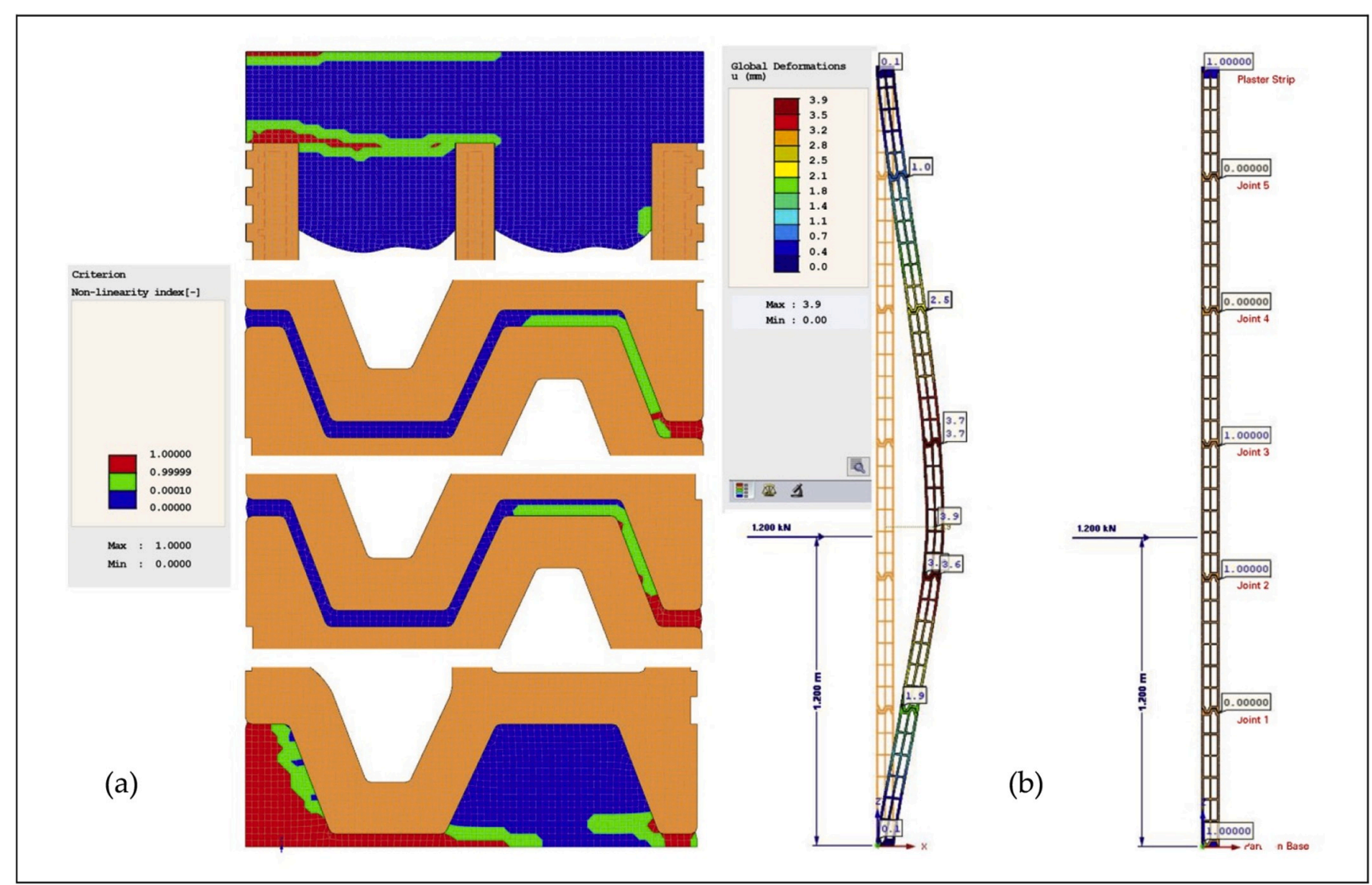

Fig. A.8. One-sheet proposed partition system for $0.80 \mathrm{kN} / \mathrm{m}$ horizontal load. (a) Fissure results at different heights. And (b), Global view specifying the deformation values. 


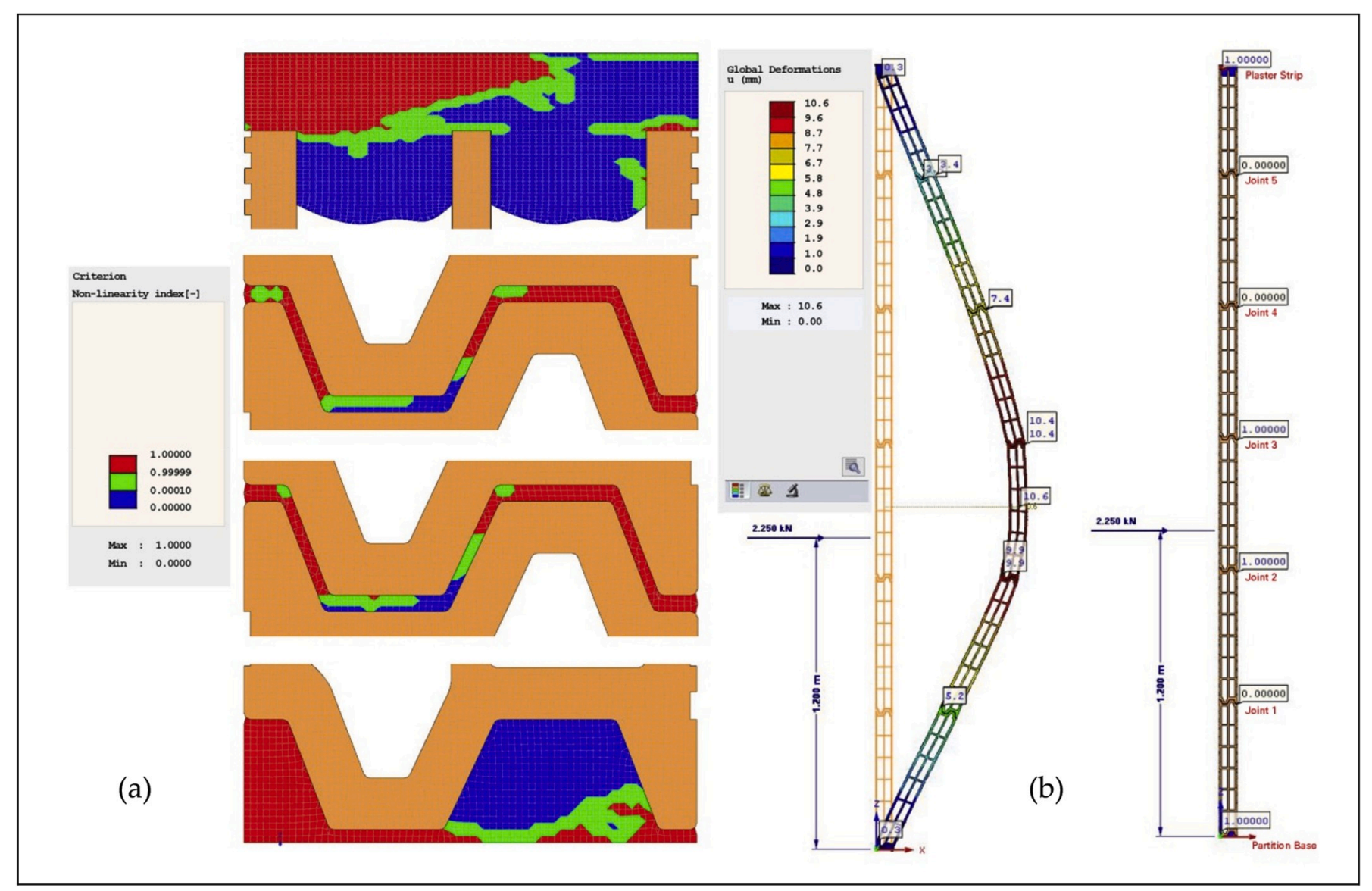

Fig. A.9. One-sheet proposed partition system for $1,50 \mathrm{kN} / \mathrm{m}$ horizontal load. (a) Fissure results at different heights. And (b), Global view specifying the deformation values. 


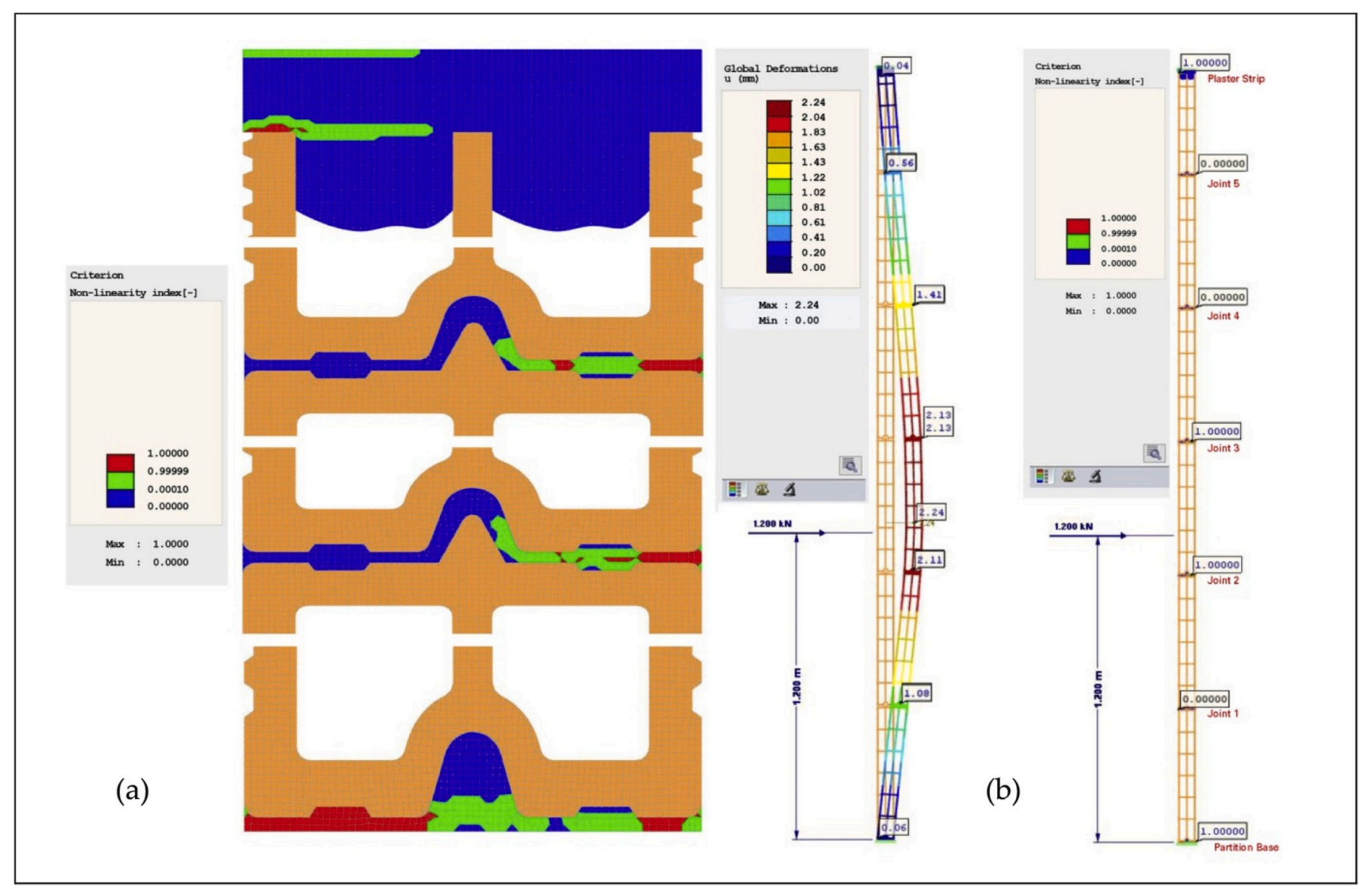

Fig. A.10. One-sheet conventional partition system for $0,80 \mathrm{kN} / \mathrm{m}$ horizontal load. (a) Fissure results at different heights. And (b), Global view specifying the deformation values. 


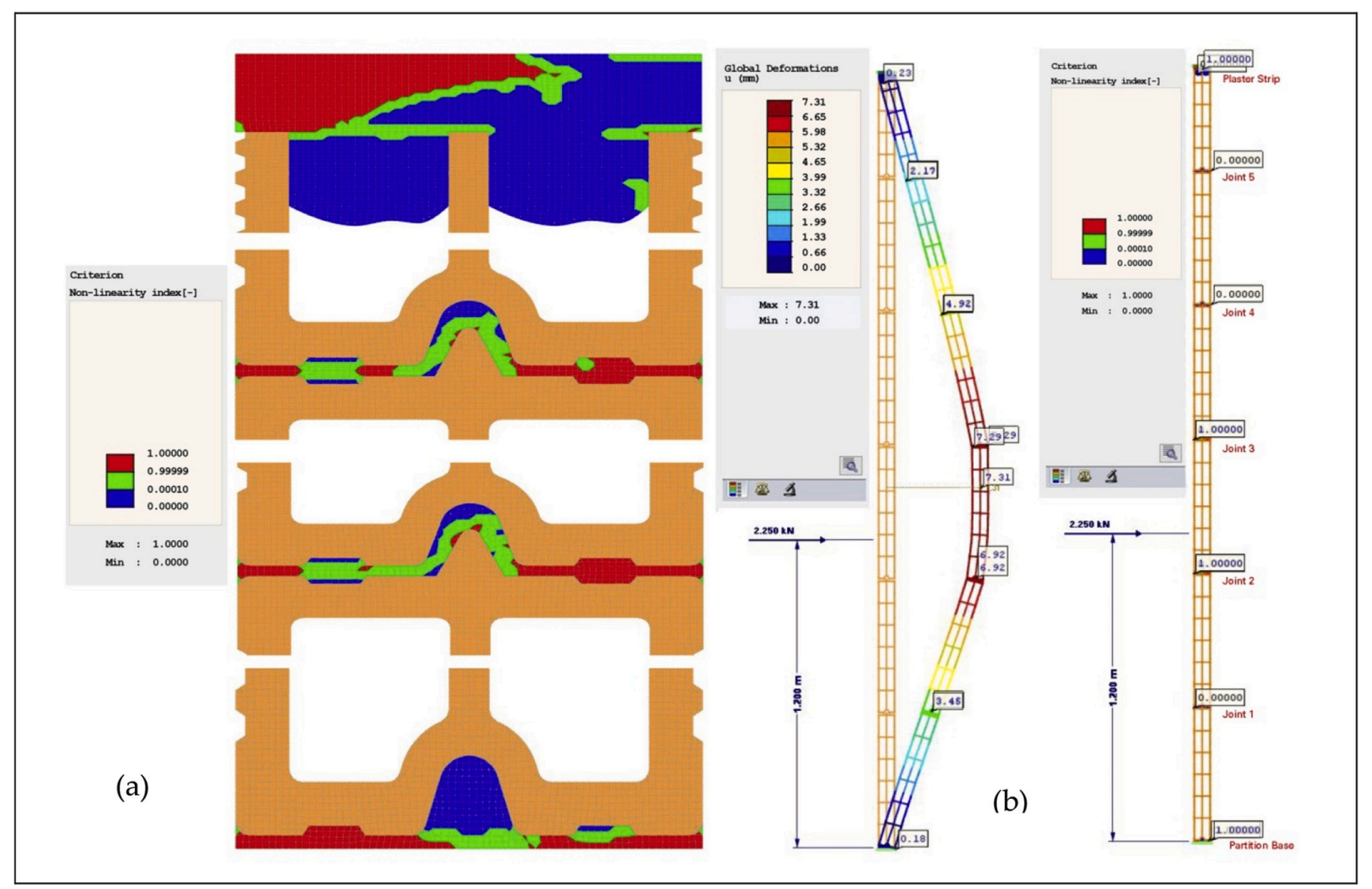

Fig. A.11. One-sheet conventional partition system for $1,50 \mathrm{kN} / \mathrm{m}$ horizontal load. (a) Fissure results at different heights. And (b), Global view specifying the deformation values.

\section{References}

[1] C.J. Kibert, Sustainable Construction: Green Building Design and Delivery, John Wiley \& Sons, New Jersey, United States of America, 2005.

[2] P.B. Lourenç, G. Vasconcelos, P. Medeiros, J. Gouveia, Vertically perforated clay brick masonry for loadbearing and non-loadbearing masonry walls, Constr. Build. Mater. 24 (11) (2010) 2317-2330.

[3] R. Broun, G. Menzies, Life cycle energy and environmental analysis of partition walls systems in UK, Procedia Eng. 21 (2011) 864e73.

[4] Shi-cong Kou, Bao-jian Zhan, Chi-sun Poon, Properties of partition wall blocks prepared with fresh concrete wastes, Constr. Build. Mater. 36 (2012) 566-571, https://doi.org/10.1016/j.conbuildmat.2011.08.063.

[5] G. Vasconcelos, P.B. Lourenço, P. Mendonça, A. Camões, R. Mateus, L. Bragança, A. G. Brito, E. Poletti, Proposal of an innovative solution for partition walls: mechanical, thermal and acoustic validation, Constr. Build. Mater. 48 (2013) 961-979, https://doi.org/10.1016/j.conbuildmat.2013.07.079.

[6] CTE_DB-HE, Codigo Tecnico de la Edificacion, Documento Basico de Proteccion frente al ruido. Available online, https://www.codigotecnico.org/images/stories /pdf/proteccionRuido/DBHR.pdf. accessed on 19 June 2019.

[7] CTE_DB-HE, Codigo Tecnico de la Edificacion. Documento Basico de Ahorro de Energía, Available online, https://www.codigotecnico.org/images/stories/pdf/a horroEnergia/DBHE.pdf. last accessed on 19 June 2019.

[8] Reza Broun, F. Gillian, Menzies, Life cycle energy and environmental analysis of partition wall systems in the UK, Procedia Eng. 21 (2011) 864-873, https://doi. org/10.1016/j.proeng.2011.11.2088.

[9] Barbara Rossi, Anne-Françoise Marique, Mauritz Glaumann, Sigrid Reiter, Lifecycle assessment of residential buildings in three different European locations, basic tool, Build. Environ. 51 (2012) 395e401, https://doi.org/10.1016/j. buildenv.2011.11.017.

[10] Soheyl Sazedj, Antonio Jose Morais, Jalali Said, Comparison of environmental benchmarks of masonry and concrete structure based on a building model, Constr. Build. Mater. 141 (2017) 36-43, https://doi.org/10.1016/j. conbuildmat.2017.02.150.

[11] Xiaodong Li, Yimin Zhu, Zhihui Zhang, An LCA-based environmental impact assessment model for construction processes, Build. Environ. 45 (2010) 766-775. https://doi:10.1016/j.buildenv.2009.08.010.
[12] Nirvan Makoond, Pela Luca, Climent Molins, Dynamic elastic properties of brick masonry constituents, Constr. Build. Mater. 199 (2019) 756-770, https://doi.org/ 10.1016/j.conbuildmat.2018.12.071.

[13] Jianli Hao, Hongping Yuan, Jing Liu, Chee Seong Chin, Weisheng Lu, A model for assessing the economic performance of construction waste reduction, J. Clean. Prod. (2019), https://doi.org/10.1016/j.jclepro.2019.05.348. Accepted Manuscript.

[14] W. Addis, J. Schouten, Principles of Design for Deconstruction to Facilitate Reuse and Recycling, CIRIA, London, 2004, p. 38 e 39.

[15] MORCEM $®$ Plaster-Based Assembly Paste for Joining Large-Format Ceramic Partitions, last accessed on 19 June 2019, https://www.grupopuma.com/es-E $\mathrm{S} /$ productos/ver/morcem-yeso-gran-formato-ce-es-es.

[16] ETAG 003, Guideline for European Technical Approval. Internal partition kits for use as non-loadbearing Wall de la EOTA Edition December, 1998/Amended April 2012.

[17] EN 1991-1-1 - Eurocode 1, Actions on Structures - Part 1-1: General Actions Densities, Self-Weight, imposed loads for buildings, 2001.

[18] Council Directive 89/106/EEC of 21 December 1988 on the Approximation of Laws, Regulations and Administrative Provisions of the Member States Relating to Construction Products. https://eur-lex.europa.eu/legal-content/en/ALL/?uri CEL EX:31989L0106 last accessed on 20 August 2019.

[19] EOTA, Determination of Impact Resistance of Panels and Panel Assemblies, Technical report TR 001, 2003.

[20] CTE DB- SE-AE, Codigo Tecnico de la Edificacion, Documento Basico: Seguridad Estructural, Acciones en la Edificacion. https://www.codigotecnico.org/images/st ories/pdf/seguridadEstructural/DBSE-AE.pdf last accessed on 20 August 2019.

[21] UNE-EN 843-2, Advanced Technical Ceramics - Mechanical Properties of Monolithic Ceramics at Room Temperature - Part 2: Determination of Young's Modulus, Shear Modulus and Poisson's Ratio (Endorsed by AENOR in January of 2007, 2006.

[22] UNE-EN 14146, Natural stone test methods - determination of the dynamic modulus of elasticity (by measuring the fundamental resonance frequency. https ://www.une.org/encuentra-tu-norma/busca-tu-norma/norma?c N0032544, 2004.

[23] ASTM C-885 - 87: "Standard Test Method for Young's Modulus of Refractory Shapes by Sonic Resonance". https://www.astm.org/Standards/C885.htm, 2012. https://www.une.org/encuentra-tu-norma/busca-tu-norma/norma?c N0038030. 
[24] ASTM C597, Standard Test Method for Pulse Velocity through Concrete. https ://www.astm.org/Standards/C597.htm, 2009.

[25] N. Ricardo, P. Baetting, Determinacion del modulo de elasticidad de la madera mediante vibraciones transversales, Maderas, Cienc. Tecnol. 3 (1-2) (2001) 44-51.

[26] J.R. Rosell, I.R. Cantalapiedra, Metodo simple para determinar el modulo de Young dinamico a partir de una excitacion por impacto aplicado a morteros de cal y cemento, Mater. Construccion 61 (301) (2011) 39-48.

[27] RFEM, version 5.15, of Dlubal Software GmbH calculation program by finite elements method (FEM). https://www.dlubal.com/en/products/rfem-fea-softwar e/what-is-rfem last accessed on 20 August 2019.

[28] J.F. Labuz, A. Zang, Rock Mech. Rock Eng. 45 (2012) 975, https://doi.org/ 10.1007/s00603-012-0281-7.

[29] Daniel C. Hammerand, Geometrically-Linear and Nonlinear Analysis of Linear Viscoelastic Composites Using the Finite Element Method Avaiable on. https://vt echworks.lib.vt.edu/bitstream/handle/10919/28893/title.pdf?sequence 1\&isAll owed y last accessed on 20 August 2019.

[30] Newton Raphson Method, Brilliant.org. Retrieved 16:54, from, https://brilliant.or g/wiki/newton-raphson-method/, June 28, 2019.

[31] CTE DB- SE-F, Codigo Tecnico de la Edificacion, Documento Basico: Seguridad Estructural, Fabrica. https://www.codigotecnico.org/images/stories/pdf/seguri dadEstructural/DBSE-F.pdf last accessed on 20 August 2019.

[32] P.B. Lourenco, G. Vasconcelos, P. Medeiros, J. Gouveia, Vertically perforated clay brick masonry for loadbearing and non-loadbearing masonry walls, Constr. Build Mater. 24 (2010) 2317-2330. https://doi:10.1016/j.conbuildmat.2010.04.010.

[33] CTE DB-HE Codigo Tecnico de la edificacion, Documento Basico. Ahorro de energía. https://www.apabcn.cat/Documentacio/areatecnica/legislacio/CTE_DB_ HE.pdf last accessed on 20 August 2019.

[34] UNE-EN ISO 10077-2:2012 Thermal Performance of Windows, Doors and Shutters - Calculation of Thermal Transmittance - Part 2: Numerical Method for Frames (ISO 10077-2:2012).

[35] CEC/CTE, Catalogo de Elementos Constructivos del Codigo Tecnico de la edificacion. http://www.anape.es/pdf/Catalogo\%20de\%20Elementos\%20Constr uctivos\%20CAT-EC-v06.3_marzo_10.pdf.

[36] UNE EN ISO 8990, Thermal insulation. determination of steady-state thermal transmission properties. calibrated and guarded hot box (iso 8990:1994). https ://www.une.org/encuentra-tu-norma/busca-tu-norma/norma?c N0013808, 1997.

[37] Z. Pezeshki, A. Soleimani, A. Darabi, S.M. Mazinani, Thermal transport in: building materials, Constr. Build. Mater. 181 (2018) 238-252, https://doi.org/10.1016/j. conbuildmat.2018.05.230.

[38] I.A. Atsonios, I.D. Mandilaras, D.A. Kontogeorgos, M.A. Founti, A comparative assessment of the standardized methods for the in-situ measurement of the thermal resistance of building walls, Energy Build. 154 (2017) 198-206, https://doi.org/ 10.1016/j.enbuild.2017.08.064.

[39] Bisco Version, 9.0w. Physibel c.v. Maldegem (Belgica). https://slideplayer.com/s lide/4174040/ last accessed on 20 August 2019.

[40] CTE DB-HE Codigo Tecnico de la edificacion. Documento Basico. Ahorro de Energía. Documento descriptivo climas de referencia. https://www.codigotecnico. org/images/stories/pdf/ahorroEnergia/20170202-DOC-DB-HE-0-Climas\%20de\% 20referencia.pdf last accessed on 20 August 2019.

[41] UNE-EN ISO 10140-2, Acoustics - Laboratory Measurement of Sound Insulation of Building Elements - Part 2: Measurement of Airborne Sound Insulation, 2011. ISO 10140-2:2010.

[42] UNE EN ISO 10140-5, Acoustics - Laboratory Measurement of Sound Insulation of Building Elements - Part 5: Requirements for Test Facilities and Equipment, 2011. ISO 10140-5:2010.

[43] UNE-EN ISO 717-1, Acoustics - Rating of Sound Insulation in Buildings and of Building Elements - Part 1: Airborne Sound Insulation, 2013. ISO 717-1:2013.

[44] CTE DB-HR Codigo Tecnico de la edificacion. Documento Basico. Proteccion Frente Al Ruido. https://www.codigotecnico.org/images/stories/pdf/proteccionRuido/ DccHR.pdf last accessed on 20 August 2019.

[45] TBE PCR for Clay Construction Products Guidance Document for Developing an EPD. http://www.teglasszovetseg.hu/index.php?option com_jdownloads\&view finish\&catid 197\&cid 1219\&lang hu last accessed on 19 November 2019.

[46] UNE-EN ISO 14025, Environmental labels and declarations - Type III environmental declarations - principles and procedures, ISO 14025:2006, https ://www.une.org/encuentra-tu-norma/busca-tu-norma/norma?c N0046196, 2010.

[47] CYPE Ingenieros, S.A. Base de Datos Generador de Precios para la Construccion. http://www.generadordeprecios.info/obra_nueva/Remates_y_ayudas/Ayudas/R ozas/Apertura_de_rozas_1_0_0_0.html last accessed on 19 November 2019. 